\title{
Transient tribo-dynamic analysis of crosshead slipper in low- speed marine diesel engines during engine startup
}

\author{
Rui LI ${ }^{1,2}$, Xianghui MENG ${ }^{1,2, *}$, Jingjin DONG ${ }^{3}$, Wenda $\mathbf{L I}^{3}$ \\ ${ }^{1}$ State Key Laboratory of Mechanical System and Vibration, Shanghai Jiaotong University, Shanghai 200240, China \\ ${ }^{2}$ School of Mechanical Engineering, Shanghai Jiaotong University, Shanghai 200240, China \\ ${ }^{3}$ China Shipbuilding Power Engineering Institute Company Limited, Shanghai 201206, China \\ Received: 25 March 2020 / Revised: 13 June 2020 / Accepted: 16 July 2020 \\ (C) The author(s) 2020.
}

\begin{abstract}
A crosshead slipper-guide system, which bears a significant thrust force, is an essential friction pair in low-speed marine diesel engines. Owing to the low moving speed of the crosshead slipper during engine startup, it is difficult to form good hydrodynamic lubrication between the crosshead slipper and guide. Therefore, a detailed analysis of the crosshead slipper during engine startup is needed. In this study, a new transient tribo-dynamic model for a crosshead slipper during the engine startup process is presented. The model consists of a mixed lubrication model of the crosshead slipper-guide and dynamic models of the piston assembly, crosshead assembly, connecting rod, and crankshaft. The tribo-dynamic performances of the crosshead slipper during startup and under the rated conditions were simulated and compared. The results show that the tribo-dynamics of the crosshead slipper during the startup process are significantly different from those under the rated conditions. Some measures beneficial for the low friction of a crosshead slipper-guide under the rated conditions may significantly increase the friction loss of the crosshead slipper-guide system during the startup process.
\end{abstract}

Keywords: low-speed marine diesel engine; crosshead slipper; engine start-up; mixed lubrication; friction loss; tribo-dynamic model

\section{Introduction}

In the shipping industry, $20 \%$ of the fuel energy is used to overcome friction, which results in significant energy waste [1]. The friction of a ship can be defined as internal or external [2]. Internal friction refers to the friction generated by various machines inside the ship, and external friction refers to the friction generated between the hull and the ocean. Research results have indicated that the friction loss of marine diesel engines is the primary source of internal friction [2-4]. To deal with a shortage of energy and environmental protection issues [5-9], the development of low-friction technology for marine diesel engines has become an urgent requirement of engine manufacturers.
Low-speed two-stroke crosshead marine diesel engines (hereafter referred to as low-speed marine diesel engines) have been widely used for propulsion power in commercial ships of more than $2 \mathrm{kt}[10,11]$ owing to their high thermal efficiency and reliability. Unlike high-speed automobile engines, low-speed marine diesel engines operate at a rotation speed lower than $300 \mathrm{rpm}$ and have a crosshead slipper-guide system allowing them to bear an enormous thrust force. The crosshead slipper-guide friction pair has an essential influence on the performance and life of low-speed marine diesel engines. The thrust force acting on the crosshead slipper leads to a large friction loss [4, 12]. In addition, the transverse movement and swing (secondary motion) of the crosshead slipper

* Corresponding author: Xianghui MENG, E-mail: xhmeng@sjtu.edu.cn 


\begin{tabular}{|c|c|c|c|}
\hline \multicolumn{4}{|c|}{ Nomenclature } \\
\hline \multirow[t]{2}{*}{$A_{1}, A_{2}$} & Lubricating area of slipper on thrust side and & $h_{c}$ & Oil film thickness of slipper \\
\hline & anti-thrust side & $I_{c}$ & Rotary inertia of slipper about its COM \\
\hline \multirow[t]{2}{*}{$a$} & Vertical distance between the crosshead pin & $I_{\mathrm{p}}$ & Rotary inertia of piston about its COM \\
\hline & center and top of slipper & $I_{\mathrm{cp}}$ & Rotary inertia of crosshead pin about its COM \\
\hline \multirow[t]{2}{*}{$b$} & Vertical distance between the center of mass & $I_{\mathrm{rod}}^{\mathrm{c}}$ & Rotary inertia of piston rod about its COM \\
\hline & $(\mathrm{COM})$ of slipper and top of slipper & $I_{\mathrm{cr}}$ & Rotary inertia of connecting rod about its COM \\
\hline $\mathrm{COM}$ & Abbreviation of "center of mass" & $j$ & Ratio of $l_{s t}$ to $l_{r t}$ \\
\hline C & Slipper-guide nominal clearance & $L$ & Length of piston rod \\
\hline$e_{\mathrm{t}}, e_{\mathrm{b}}$ & $\begin{array}{l}\text { Eccentricities of slipper at the top and bottom } \\
\text { ends }\end{array}$ & $L_{1}$ & $\begin{array}{l}\text { Vertical distance between COM of piston and } \\
\text { top end of piston skirt }\end{array}$ \\
\hline \multirow[t]{2}{*}{$e_{\mathrm{tp}}, e_{\mathrm{bp}}$} & Eccentricities of piston skirt at the top and & $L_{2}$ & COM of piston and bottom end of piston skirt \\
\hline & bottom ends & $L_{3}$ & Length of slipper \\
\hline \multirow[t]{2}{*}{$F_{3}$} & Force of slipper from crosshead pin in $X$ & $l_{\mathrm{rt}}^{3}$ & Length of connecting rod \\
\hline & direction & $M_{1}$ & Moment of piston from bolt \\
\hline \multirow[t]{2}{*}{$F_{y}$} & Force of slipper from crosshead pin in $Y$ & $M_{2}$ & Moment of piston rod from bolt \\
\hline & & $M_{c}$ & Moment of $F_{c}$ about the crosshead pin center \\
\hline$F_{c}$ & Total normal force acting on slipper from & $M_{i c}$ & Inertial moment of slipper \\
\hline \multirow{2}{*}{$F_{c f}$} & & $M_{\text {ip }}$ & Inertial moment of piston \\
\hline & $\begin{array}{l}\text { Total friction force acting on slipper from } \\
\text { guide }\end{array}$ & $M_{\text {icp }}$ & Inertial moment of crosshead pin \\
\hline \multirow{2}{*}{$F_{c s x}$} & Force of connecting rod from crankshaft i & $M_{\text {irod }}$ & Inertial moment of piston rod \\
\hline & direction & $m_{c}$ & Mass of slipper \\
\hline \multirow[t]{2}{*}{$F_{c s y}$} & Force of connecting rod from crankshaft in $Y$ & $m_{\mathrm{p}}$ & Mass of piston \\
\hline & direction & $m_{\mathrm{cp}}$ & Mass of crosshead pin \\
\hline \multirow{12}{*}{$\begin{array}{l}F_{\text {ic1 }} \\
F_{\text {ic2 }} \\
F_{\text {icp1 }} \\
F_{\text {icp2 }} \\
F_{\text {ip1 }} \\
F_{\text {ip2 }} \\
F_{\text {irod1 }} \\
F_{\text {irod2 } 2} \\
F_{\text {icrx }} \\
F_{\text {icry }} \\
F_{p}\end{array}$} & Reciprocating inertial force of slipper & $m_{\text {rod }}$ & Mass of piston rod \\
\hline & Transverse inertial force of slipper & $m_{\mathrm{cr}}$ & Mass of connecting rod \\
\hline & Reciprocating inertial force of crosshead pin & $p$ & Oil film pressure \\
\hline & Transverse inertial force of crosshead pin & $p_{\mathrm{c}}$ & Contact pressure \\
\hline & Reciprocating inertial force of piston & $R$ & Piston radius \\
\hline & Transverse inertial force of piston & $R_{\mathrm{c}}$ & Crank radius \\
\hline & Reciprocating inertial force of piston rod & $R_{\text {pin }}$ & Crosshead pin radius \\
\hline & Transverse inertial force of piston rod & $U=\dot{Y}_{c}$ & Longitudinal velocity of crosshead slipper \\
\hline & Connecting rod inertial force in $X$ direction & $w$ & Half of the height of slipper \\
\hline & Connecting rod inertial force in $Y$ direction & $x_{1}, y_{1}$ & Local coordinate system on the crosshead slipper \\
\hline & Total normal force acting on piston skirt from & $X, Y$ & Global coordinate system \\
\hline & cylinder liner & $Y_{c}$ & Longitudinal displacement of crosshead \\
\hline \multirow[t]{2}{*}{$F_{\mathrm{pf}}$} & Total friction force acting on piston skirt & & assembly and piston assembly \\
\hline & from cylinder liner & $\sigma$ & Composite roughness of slipper and guide \\
\hline$F_{x 1}$ & Force of piston from bolt in $X$ direction & $\theta$ & Connecting rod angle \\
\hline$F_{x 2}$ & Force of piston rod from bolt in $X$ direction & $\varphi$ & Crack angle \\
\hline$F_{y 1}$ & Force of piston from bolt in $Y$ direction & $\phi_{x}, \phi_{y}$ & Pressure flow factors \\
\hline$F_{y^{2}}$ & Force of piston rod from bolt in $Y$ direction & $\phi_{c}$ & Contact factor \\
\hline$f\left(x_{1}, y_{1}\right)$ & Profile of slipper & & Shear flow factor \\
\hline & Gravity of slipper & $\phi_{f}, \phi_{f s}, \phi_{f y}$ & Sp Shear stress factors \\
\hline$G_{\text {cp }}$ & Gravity of crosshead pin & $\mu$ & Dynamic lubricant viscosity \\
\hline$G_{\mathrm{p}}$ & Gravity of piston & $\omega=\dot{\varphi}$ & Rotation speed of crankshaft \\
\hline$G_{\text {rod }}^{p}$ & Gravity of piston rod & $\gamma_{p}$ & Attitude angle of piston \\
\hline$G_{\mathrm{cr}}$ & Gravity of connecting rod & $\mu_{f}$ & Friction coefficient of asperity contact \\
\hline
\end{tabular}


also have an important influence on the vibration and noise of the engine [4]. Therefore, the performance of the crosshead slipper-guide system is a significant concern during the development of low-speed marine engines. However, research on the tribo-dynamic performance of a crosshead slipper-guide system remains scarce. Scholars have paid more attention to the tribological phenomena of other friction pairs such as piston rings [13-16], crosshead bearings [17, 18], and crankpin bearings [19] in low-speed marine diesel engines. Moreover, such studies have only been carried out under the rated conditions. Abanteriba [20-22] established a simplified model of the lubrication performance of a crosshead slipper, focusing on the minimum oil film thickness and friction loss of the crosshead slipper under the rated conditions. Considering the secondary motion of the crosshead slipper and coupling effects between the piston skirtliner friction pair and crosshead slipper-guide friction pair, the authors of this study established a more accurate tribo-dynamic model to analyze the performance of the crosshead slipper under the rated conditions [4, 12].

Engines usually operate under complicated and variable operating conditions. The engine startup process, which is quite different from the rated conditions, requires special attention. Owing to the low rotation speed of the crankshaft and the low moving speed of the crosshead slipper during the engine startup, it is difficult to form a good hydrodynamic lubrication between the crosshead slipper and guide. Under a huge thrust force, insufficient lubrication may lead to severe contact and wear. Therefore, a detailed analysis of the crosshead slipper during engine startup is needed. At present, most research in this area has focused on the startup process of high-speed automobile engines. Scholars have conducted in-depth studies on performance prediction models and optimization schemes of critical friction pairs in automotive engines during the startup process [23-28]. However, related studies on the startup process of low-speed marine diesel engines have yet to be reported. Compressed air is generally used to start low-speed marine diesel engines, which are significantly different from automobile engines. The structures of both types of engines are also extremely different. It is therefore necessary to carry out targeted research on low-speed marine diesel engines.

Herein, we extend such studies to include the startup process of low-speed marine diesel engines. The rotation speed of the crankshaft will be considered as a motion variable and is solved along with the dynamic parameters of the crosshead slipper. First, according to the motion and force analysis of the components in low-speed marine diesel engines, the dynamic models of the piston assembly, crosshead assembly, connecting rod, and crankshaft are established. The dynamic models are then coupled with the mixed lubrication models of the crosshead slipper-guide system and the piston skirt-liner system. Finally, the tribo-dynamic model of the crosshead slipper during the startup process is obtained. The effects of the lubricant temperature, crosshead slipper-guide nominal contact area, crosshead slipper-guide clearance, and crosshead slipper profile on the tribo-dynamics of the crosshead slipper during the startup process are explored and compared with those under the rated conditions. To the best of the authors' knowledge, the present study marks the first time such a model and its analysis have been described.

\section{Mathematical model}

A low-speed marine diesel engine is a typical multi-body mechanical system. Figure 1(a) shows the main moving parts of a six-cylinder low-speed marine diesel engine. The piston assembly, crosshead assembly, and connecting rod of only one cylinder are shown in the figure. The top of the piston rod is rigidly connected to the piston by a bolt. The bottom of the piston rod is also rigidly connected to the crosshead pin by a bolt. The connecting rod converts the reciprocating motion of the piston into the rotation of the crankshaft, thereby pushing the ship forward. The crosshead slipper focused on in this article is an important part of the crosshead assembly, the details of which are shown in Fig. 1(b). It can be seen that the crosshead assembly mainly includes the crosshead pin, crosshead slippers, and crosshead bearings. The crosshead pin is connected to the connecting rod by a revolute joint, forming a crosshead bearing. At the same time, the crosshead pin is also connected to the 


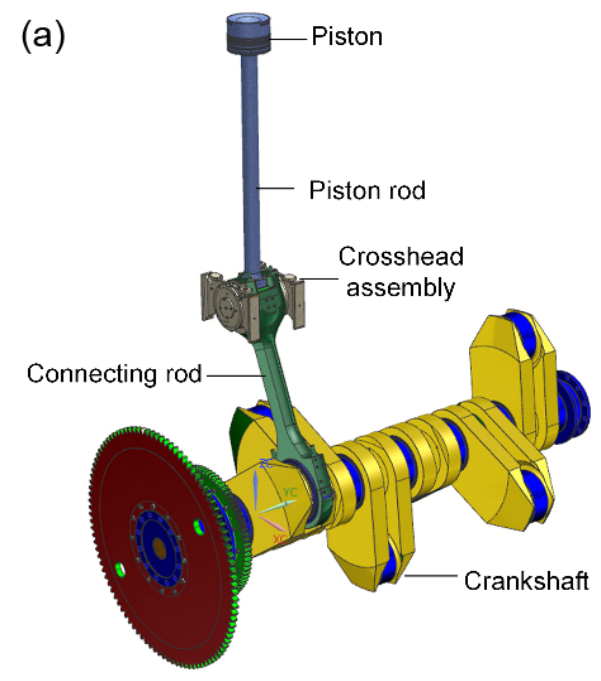

(b)

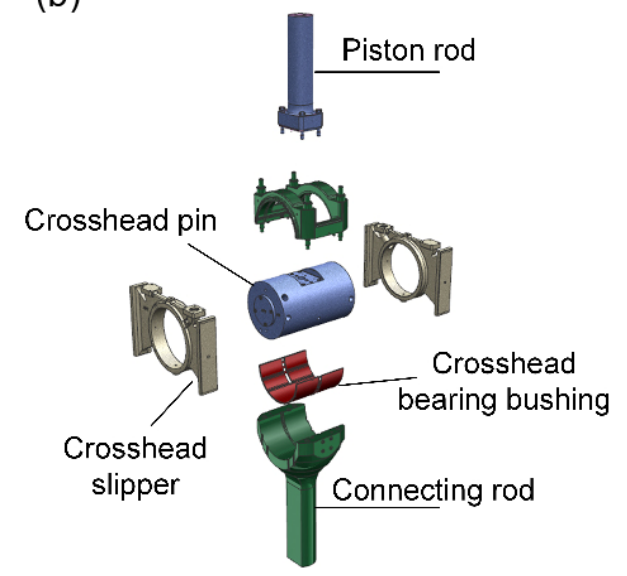

(c)

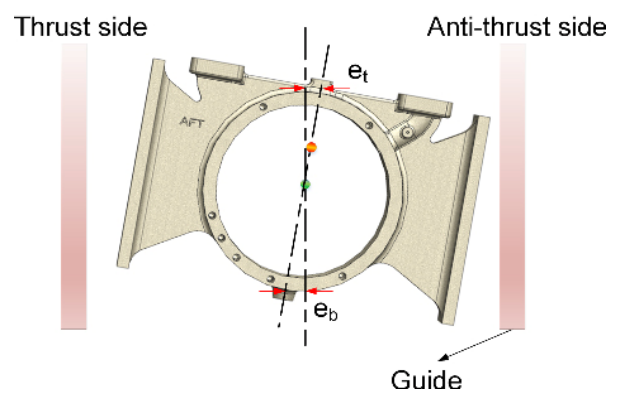

Fig. 1 Details of the six-cylinder low-speed marine diesel engine: (a) main moving components, (b) details of crosshead assembly, and (c) secondary motion of crosshead slipper.

crosshead slipper by a revolute joint.

The crosshead slipper and guide constitute a translational joint, which is the friction pair focused on in this study. In addition to the reciprocating movement in the longitudinal direction, the crosshead slipper moves laterally with a swinging motion, as shown in Fig. 1(c), which is called the secondary motion.
This can be described by the transverse displacement at the top and bottom ends of the crosshead slipper $\left(e_{\mathrm{t}}, e_{\mathrm{b}}\right.$ in Fig. 1(c)). In our previous study, we established a tribo-dynamic model that couples the dynamics of the crosshead assembly, piston assembly, and connecting rod with the crosshead slipper-guide and piston skirt-liner friction pairs. Under the engine rated conditions, an analysis of the tribo-dynamics of the crosshead slipper has been carried out $[4,12,29$, 30]. In our previous study, the crankshaft speed was set to a fixed value. In this study, this assumption is dropped, and a new startup model is established by adding a dynamic analysis of the crankshaft. The tribo-dynamic performance of the crosshead slipper during the engine startup process is discussed in depth.

\subsection{Dynamic models of piston-crosshead assembly connecting rod-crankshaft}

In this section, a force analysis of the piston assembly, crosshead assembly, connecting rod, and crankshaft is described. A force analysis of the piston-piston rod-crosshead pin system is shown in Figs. 2(a-c). The detailed dynamic equations are the same as in our previous work [4, 12], and are shown in the Appendix; they have not repeated here for simplicity.

The force analysis of the crosshead slipper is shown in Fig. 2(d). The detailed equations refer to our previous studies [4, 12] and are also not repeated here for simplicity. The related content is also shown in the Appendix.

The displacement, velocity, and acceleration of the piston assembly and crosshead assembly in the $Y$ direction can be expressed as below. Compared with the previous study on the rated conditions, the formula of acceleration $\ddot{Y}_{c}$ changed owing to the acceleration of the crankshaft $\ddot{\varphi}$.

$$
\begin{gathered}
Y_{c}=l_{\mathrm{rt}}+R_{c}-\left(l_{\mathrm{rt}}^{2}-B_{1}^{2}\right)^{0.5}-R_{c} \cos \varphi \\
\dot{Y}_{c}=R_{c} \dot{\varphi} \sin \varphi+R_{c} \dot{\varphi} B_{1} \cos \varphi\left(l_{\mathrm{rt}}^{2}-B_{1}^{2}\right)^{-0.5} \\
\ddot{Y}_{c}=I_{1} \ddot{\varphi}+\left(I_{2}+I_{3}\right) \dot{\varphi}^{2}
\end{gathered}
$$

where $B_{1}=R_{c} \cdot \sin \varphi, l_{\mathrm{rt}}$ is the length of the connecting rod, and $R_{c}$ is the crank radius. In addition, $\varphi$ is the crank angle, and $\dot{\varphi}$ is the crankshaft rotation speed. 


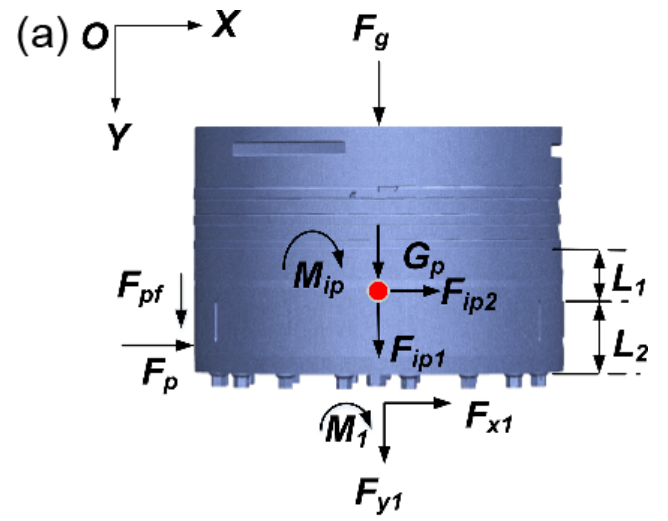

(b)

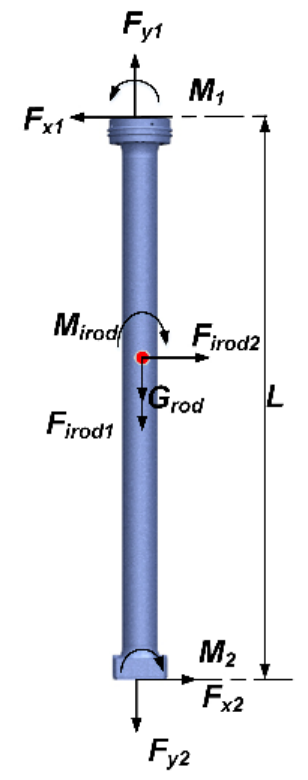

(c)

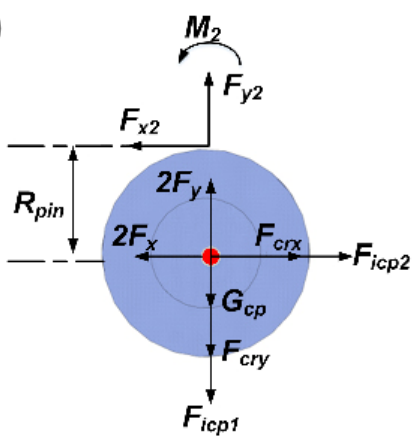

(d)

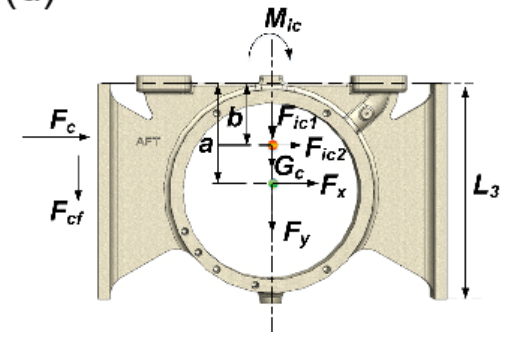

Fig. 2 Force analysis of (a) piston, (b) piston rod, (c) crosshead pin, and (d) crosshead slipper.
The three intermediate variables $\left(I_{1}, I_{2}\right.$, and $\left.I_{3}\right)$ are as follows:

$$
\begin{aligned}
& I_{1}=\left(l_{\mathrm{rt}}^{2}-B_{1}^{2}\right)^{-0.5} R_{c}^{2} \sin \varphi \cos \varphi+R_{c} \sin \varphi \\
& I_{2}=R_{c} \cos \varphi+\left(R_{c} B_{1} \cos \varphi\right)^{2}\left(l_{\mathrm{rt}}^{2}-B_{1}^{2}\right)^{-1.5} \\
& I_{3}=\left[\left(R_{c} \cos \varphi\right)^{2}-R_{c} B_{1} \sin \varphi\right]\left(l_{\mathrm{rt}}^{2}-B_{1}^{2}\right)^{-0.5}
\end{aligned}
$$

The inertial forces of the piston, piston rod, crosshead pin, and crosshead slipper can be written as follows. The values have also changed compared with the previous studies on the rated conditions [4, 12], which was caused by the acceleration of the crankshaft.

$$
\begin{aligned}
F_{\text {ip }} & =-m_{p} \ddot{Y}_{c} \\
F_{\text {irod }} & =-m_{\text {rod }} \ddot{Y}_{c} \\
F_{\text {icp }} & =-m_{\text {cp }} \ddot{Y}_{c} \\
F_{\text {ic }} & =-m_{c} \ddot{Y}_{c}
\end{aligned}
$$

The calculation methods of the transverse inertial forces $F_{\text {ip2 }}, F_{\text {irod2 }}, F_{\text {icp2 }}$, and $F_{\text {ic2 }}$, and the inertial moments $M_{\text {ip }}, M_{\text {irod }}, M_{\text {icp }}$, and $M_{\text {ic }}$, are consistent with those of the previous studies [4, 12], and are not repeated here for simplicity.

The force analysis of the connecting rod is shown in Fig. 3(a). The equations, shown in the Appendix, are based on d'Alembert's principle, which is consistent with our previous study on the rated conditions. From the force analysis, the relationship between $F_{c s x 1}$ and $F_{c s y 1}$ can be obtained as follows:

$$
\begin{aligned}
F_{c s y 1}= & -\left(G_{\mathrm{cp}}+2 G_{c}+G_{\mathrm{rod}}+G_{\mathrm{p}}+G_{\mathrm{cr}}\right) \\
& -\left(F_{\mathrm{ip} 1}+2 F_{\mathrm{ic} 1}+F_{\mathrm{icp} 1}+F_{\mathrm{irod} 1}+F_{i c r y 1}\right)-F_{g}-F_{p f}-2 F_{c f}
\end{aligned}
$$

$F_{c s x 1}=\frac{-M_{\mathrm{icr}}+F_{c s y 1} l_{\mathrm{rt}} \sin \theta-F_{i c r x} l_{r s} \cos \theta+\left(G_{\mathrm{cr}}+F_{i c r y}\right) l_{r s} \sin \theta}{l_{\mathrm{rt}} \cos \theta}$

This relationship is key to determining the crankshaft speed.

The connecting rod angle $\theta$, angular velocity $\dot{\theta}$, and angular acceleration $\ddot{\theta}$ can be expressed as below. Compared with the study on the rated conditions, the acceleration of the connecting rod angle $\ddot{\theta}$ is not 
equal to zero.

$$
\begin{gathered}
\theta=\arctan \left(\frac{R_{c} \sin \varphi}{\sqrt{l_{r t}^{2}-\left(R_{c} \sin \varphi\right)^{2}}}\right) \\
\dot{\theta}=\dot{\varphi} \frac{R_{c} \cos \varphi}{\sqrt{l_{\mathrm{rt}}^{2}-\left(R_{c} \sin \varphi\right)^{2}}} \\
\ddot{\theta}=I_{4} \ddot{\varphi}+I_{5} \dot{\varphi}^{2}
\end{gathered}
$$

The two intermediate variables, $I_{4}$ and $I_{5}$, can be obtained as follows:

$$
\begin{gathered}
I_{4}=\frac{R_{c} \cos \varphi}{l_{\mathrm{rt}} \cos \theta} \\
I_{5}=-\left[\left(\frac{R_{c} \cos \varphi}{l_{\mathrm{rt}} \cos \theta}\right)^{2} \tan \theta+\frac{R_{c} \sin \varphi}{l_{\mathrm{rt}} \cos \theta}\right]
\end{gathered}
$$

Correspondingly, the rotational inertia moment of the connecting rod can be expressed as indicated below. Compared with the previous formula for the rated conditions, the effect of the acceleration of the crankshaft is considered.

$$
M_{\mathrm{icr}}=-I_{\mathrm{cr}}\left(I_{4} \ddot{\varphi}+I_{5} \dot{\varphi}^{2}\right)
$$

The inertia forces of the connecting rod in the $X$ and $Y$-directions are shown below. In contrast to the previous formulas [4], the effects of the angular acceleration of the crankshaft and connecting rod are considered.

$$
\begin{gathered}
F_{i c r x}=-m_{\mathrm{cr}}\left[(1-j) R_{c}\left(-\sin \varphi \dot{\varphi}^{2}+\ddot{\varphi} \cos \varphi\right)\right. \\
\left.+j\left(1-\frac{a}{L_{3}}\right) \ddot{e}_{t}+j \frac{a}{L_{3}} \ddot{e}_{b}\right] \\
F_{i c r y}=-m_{c r}\left[j l_{r t}\left(\cos \theta \dot{\theta}^{2}+\ddot{\theta} \sin \theta\right)+R_{c}\left(\cos \varphi \dot{\varphi}^{2}+\ddot{\varphi} \sin \varphi\right)\right]
\end{gathered}
$$

where $j=l_{s t} / l_{r t}$, as shown in Fig. 3(a), and $m_{\mathrm{cr}}$ is the mass of the connecting rod.

Unlike the previous study on the rated conditions, the rotation speed of the crankshaft changes during the startup process. Therefore, the dynamic equations of the crankshaft need to be determined. Figure 3(b) shows the details of the crankshaft. The centroid of the crankshaft (including the attachments) can be approximated along the centerline of the rotation. (a)
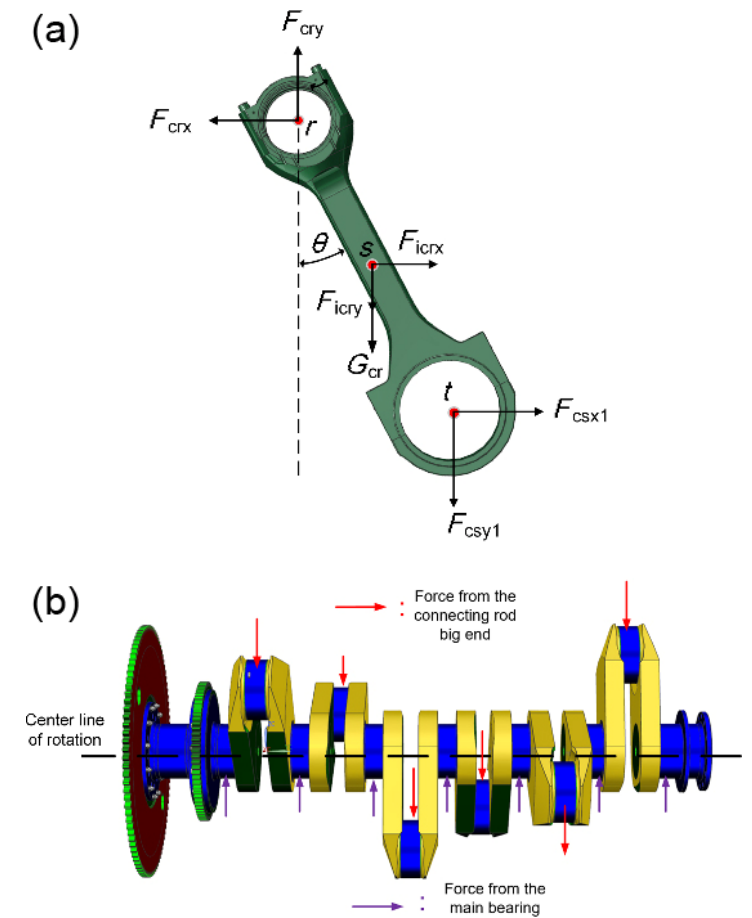

(c)

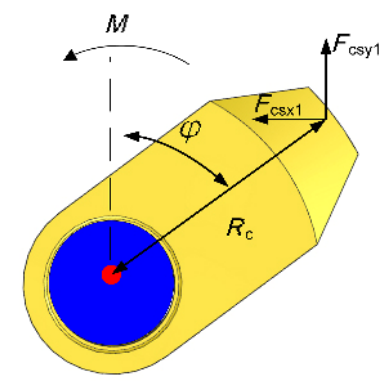

Fig. 3 (a) Force analysis of connecting rod, and (b, c) force analysis and rotation analysis of crankshaft, respectively.

The crankshaft rotation is driven by the connecting rod force of each cylinder. As shown in the figure, the crankshaft is mainly subjected to the force from the connecting big end of the rod and the force of the main bearings. These two types of forces ensure the balance of the force on the crankshaft. Because the current study focuses on the change in the crankshaft speed during the startup process, the primus equations are used for the rotation, the details of which regarding the force balance are not introduced here. Taking the start of a single cylinder as an example, the rotation equation of the crankshaft, shown in Fig. 3(c), is as follows:

$$
-F_{c s x 1} R_{c} \cos \varphi-F_{c s y 1} R_{c} \sin \varphi-M=J \ddot{\varphi}
$$

The calculation method of $F_{c s x 1}$ and $F_{c s y 1}$ is introduced 
in Eqs. (11) and (12). At a specific time, when the crank angle is determined, $F_{c s x 2}, F_{c s y 2}, \ldots, F_{c s x 6}$, and $F_{c s y 6}$, which represent the connecting rod force acting on the crankshaft in other cylinders, can be obtained through a similar method, and a single-cylinder model can easily be converted into a multi-cylinder model. However, the number of motion variables increases significantly. Here, $M$ is the resistance moment on the shaft, which mainly includes the drag torque generated by the main bearings and propeller, and $J$ is the total rotary inertia of the crankshaft (including the attachments). In the current study, the lubrication of the main bearings on the crankshaft is not included in the tribo-dynamic model because the focus is the tribology of the crosshead slipper-guide friction pair. Considering the clearance between the crankshaft and the main bearings, the independent motion variables of the tribo-dynamic model will increase. The difficulty and cost of solving the model will also significantly increase.

Finally, the tribo-dynamic model, which contains four independent motion variables $\mathrm{e}_{\mathrm{t}}, \mathrm{e}_{\mathrm{b}}, \mathrm{e}_{\mathrm{tp}}$, and $\varphi$ is obtained after eliminating the constraint reaction forces $F_{c r x}, F_{c r y}, F_{c s x}, F_{c s y}, F_{x}$, and $F_{y}$. Compared with the previous approach for the rated conditions, the tribo-dynamic model is more sophisticated. The rotation speed of the crankshaft becomes an unknown variable to be solved, and the matrix has four dimensions. The intermediate variables $A_{11}-A_{44}$ and $C_{F}-C_{o}$ are shown in the Appendix.

$$
\left[\begin{array}{cccc}
A_{11} & A_{12} & A_{13} & A_{14} \\
A_{21} & A_{22} & A_{23} & A_{24} \\
A_{31} & A_{32} & A_{33} & A_{34} \\
A_{41} & A_{42} & A_{43} & A_{44}
\end{array}\right]\left[\begin{array}{c}
\ddot{\mathrm{e}}_{\mathrm{t}} \\
\ddot{\mathrm{e}}_{\mathrm{b}} \\
\ddot{\mathrm{e}}_{\mathrm{tp}} \\
\ddot{\varphi}
\end{array}\right]=\left[\begin{array}{c}
C_{F} \\
C_{S} \\
C_{T} \\
C_{o}
\end{array}\right]
$$

\subsection{Mixed lubrication model of crosshead slipper- guide friction pair}

When solving the presented tribo-dynamic model, the normal force $F_{c}$, the friction force $F_{c f}$ between the crosshead slipper and guide, and the corresponding torque $M_{c}, M_{c f}$ need to be determined through a mixed lubrication analysis. Similarly, these forces and moments of the piston skirt also need to be calculated. Because both are lubricated translational joints, the calculation method is similar. This section introduces the details of the mixed lubrication model of the crosshead slipper-guide. The processing method of the piston skirt-cylinder liner is identical, as shown in a previous study [12].

Figure 4 shows a lubrication diagram of the crosshead slipper-guide friction pair. When the crosshead slipper moves back and forth in the longitudinal direction, the lubricant in the clearance between the crosshead slipper and guide will produce a hydrodynamic effect [31]; when the crosshead slipper has a transverse displacement and swing (secondary motion), a squeezing effect is generated. Under these two effects, the lubricant will create a pressure field to separate the crosshead slipper from the guide plate, reducing the friction and wear. Considering the effect of the surface roughness, Patir and Cheng [32, 33] proposed an average Reynolds equation to solve the pressure of the lubricant, the equation of which for the translational joints is shown in the following [27]:

$$
\begin{aligned}
& \frac{\partial}{\partial x_{1}}\left(\phi_{x} \frac{h_{c}^{3}}{12 \mu} \frac{\partial p}{\partial x_{1}}\right)+\frac{\partial}{\partial y_{1}}\left(\phi_{y} \frac{h_{c}^{3}}{12 \mu} \frac{\partial p}{\partial y_{1}}\right)= \\
& \frac{-U}{2}\left(\phi_{c} \frac{\partial h_{c}}{\partial y_{1}}+\sigma \frac{\partial \phi_{s}}{\partial y_{1}}\right)+\phi_{c} \frac{\partial h_{c}}{\partial t}
\end{aligned}
$$

(a) Thrust side

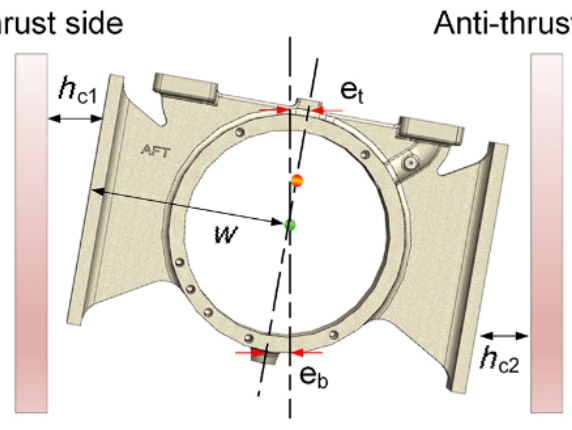

(b)

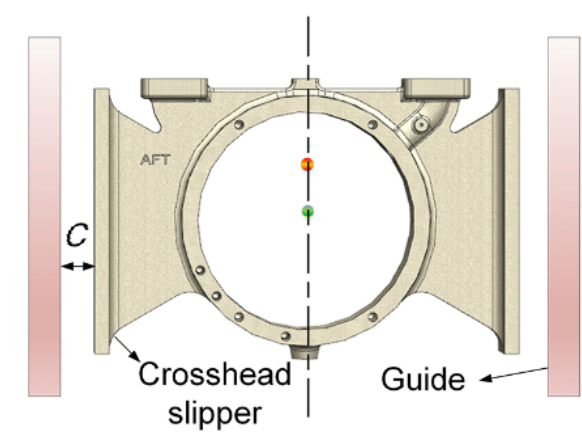

Fig. 4 (a) Description of oil film thickness of the crosshead slipper and (b) the nominal clearance between the crosshead slipper and guide. 
where $p$ is the average lubricant pressure, and $h_{c}$ is the lubricant film thickness, as shown in Fig. 4(a). In addition, $\mu$ is the lubricant viscosity, and $\sigma$ represents the composite surface roughness of the crosshead slipper and guide. Moreover, $U=\dot{Y}_{c}$ is the velocity of the crosshead slipper in the longitudinal direction, and $x_{1}, y_{1}$ represent the local coordinates on the crosshead slipper, where $x_{1}$ is the coordinate axis along the width direction, and $y_{1}$ is the coordinate axis along the moving direction. In addition, $\phi_{x}$, $\phi_{y}$ are pressure flow factors, and $\phi_{s}$ represents the shear flow factor [32]. Finally, $\phi_{c}$ is the contact factor [34].

For the marine diesel engine considered in this study, the grade of lubricating oil used for the crosshead slipper is CD40, and its viscosity-temperature characteristics can be approximated through the following formula [4]: $\mu=0.12954 e^{-0.0394(T-40)}$. In the current study, the viscosity-pressure effect of the lubricant is not considered for simplicity because the oil film pressure is always at a small level owing to the large nominal contact area of the crosshead slipper -guide.

The oil film thickness $h_{c}$, as shown in Fig. 4(a), can be obtained through the following formulas [4, 12]:

$$
\begin{aligned}
& h_{\mathrm{c} 1}=C+\left[e_{t}-\left(e_{t}-e_{b}\right) \frac{y_{1}}{L_{3}}\right]+f\left(x_{1}, y_{1}\right), \\
& h_{\mathrm{c} 2}=C-\left[e_{t}-\left(e_{t}-e_{b}\right) \frac{y_{1}}{L_{3}}\right]+f\left(x_{1}, y_{1}\right)
\end{aligned}
$$

where $C$ is the nominal clearance between the crosshead slipper and guide, and is defined as the clearance between the crosshead slipper and the guide when the crosshead slipper is located on the vertical central axis of the guide without a secondary motion, as shown in Fig. 4(b). Here, $e_{t}$ and $e_{b}$ represent the transverse displacement in the top and bottom ends of the crosshead slipper, respectively. In addition, $f\left(x_{1}, y_{1}\right)$ is the profile of the crosshead slipper. Owing to the large size of the crosshead slipper, the oil film pressure is not excessively high. Therefore, the elastic deformation is temporarily ignored to improve the efficiency of the calculation.

To simplify the calculation, a fully flooded inlet boundary condition was adopted in the current study.
The related numerical method for dealing with the oil transport and starved lubrication conditions can be found in previous studies $[10,15]$.

The average Reynolds equation belongs to the elliptic partial differential equation, and the boundary conditions need to be determined when solving it. The crosshead slipper-guide friction pair can be expressed as follows:

$$
\begin{array}{ll}
p\left(x_{1}, y_{1}\right)=0 & x_{1}=0, B \\
p\left(x_{1}, y_{1}\right)=0 & y_{1}=0, L_{3}
\end{array}
$$

where $L_{3}$ and $B$ represent the length and width of the crosshead slipper, respectively. The above boundary conditions indicate that the oil film pressure at the edge of the crosshead slipper is equal to the atmospheric pressure.

In the divergent wedge between the crosshead slipper and guide, a cavitation exists in the oil film [35], and the cavitation boundary conditions need to be specified. At present, the Reynolds and JFO boundary conditions are widely used. The JFO cavitation boundary condition satisfying the oil conservation in the cavitation boundary is more perfect in theory $[36,37]$. The calculation efficiency of the Reynolds boundary condition is better, and the accuracy is acceptable in most cases [38-41]. In the current study, the Reynolds boundary condition was adopted. The cavitation boundary condition can be expressed according to the following Reynolds boundary condition [10]:

$$
p\left(x_{1}, y_{1}\right)=0, \frac{\partial p}{\partial y_{1}}=0 \quad y_{1}=y^{*}
$$

where $y^{*}$ is the cavitation position. In the iterative solution process of the oil film pressure field, the oil film pressure is set to zero when it is a negative value. The converged oil film pressure field then approximately satisfies the Reynolds boundary condition.

When the crosshead slipper operates at low speed (e.g., the startup process) or high load, an asperity contact may occur. The G-T model, which assumes that the asperity heights obey a Gaussian distribution, is used to calculate the asperity contact pressure in the current study, and can be expressed as follows $[42,43]$ : 


$$
p_{c}=\frac{16 \sqrt{2}}{15} \pi(\eta \beta \sigma)^{2} E^{\prime} \sqrt{\frac{\sigma}{\beta}} F_{\frac{5}{2}}\left(H_{\sigma}\right)
$$

where $E^{\prime}$ is the equivalent elastic modulus of the two rough surfaces and can be written as

$$
E^{\prime}=\frac{E_{1} E_{2}}{E_{2}\left(1-v_{1}^{2}\right)+E_{1}\left(1-v_{2}^{2}\right)}
$$

where $E_{1}$ and $E_{2}$ are the elastic moduli of the two contact bodies, $v_{1}, v_{2}$ are the Poisson's ratio, $\eta$ indicates the asperity density, and $\beta$ is the average asperity summit radius. In addition, $H_{\sigma}=\frac{h}{\sigma}$ represents the ratio of the oil film thickness to the composite RMS roughness of the friction pair, and $F_{\frac{5}{2}}\left(H_{\sigma}\right)$ is the Gaussian probability density function. Its approximate formula, presented by $\mathrm{Hu}$ et al., can be expressed as follows [41]:

$$
F_{\frac{5}{2}}\left(H_{\sigma}\right)=\left\{\begin{array}{cc}
4.4086 \times 10^{-5}\left(4-H_{\sigma}\right)^{6.804} & H_{\sigma} \leq 4 \\
0 & H_{\sigma}>4
\end{array}\right.
$$

After determining the oil film pressure $p$ and the asperity contact pressure $p_{c}$, the total side force $F_{c}$, friction force $F_{c f}$, and the corresponding torques $M_{c}$ and $M_{c f}$ can finally be expressed as follows:

$$
\begin{gathered}
F_{C}=\iint_{A_{1}}\left[p\left(x_{1}, y_{1}\right)+p_{c}\left(x_{1}, y_{1}\right)\right] d x_{1} d y_{1} \\
-\iint_{A_{2}}\left[p\left(x_{1}, y_{1}\right)+p_{c}\left(x_{1}, y_{1}\right)\right] d x_{1} d y_{1} \\
M_{C}=\iint_{A_{1}}\left[p\left(x_{1}, y_{1}\right)+p_{c}\left(x_{1}, y_{1}\right)\right]\left(a-y_{1}\right) . \\
d x_{1} d y_{1}-\iint_{A_{2}}\left[p\left(x_{1}, y_{1}\right)+p_{c}\left(x_{1}, y_{1}\right)\right]\left(a-y_{1}\right) d x_{1} d y_{1} \\
F_{c f}=\iint_{A_{1}}\left[\tau x_{1}, y_{1}-\frac{|U|}{U} \mu_{f} p_{c}\left(x_{1}, y_{1}\right)\right] d x_{1} d y_{1} \\
+\iint_{A_{2}}\left[\tau x_{1}, y_{1}-\frac{|U|}{U} \mu_{f} p_{c}\left(x_{1}, y_{1}\right)\right] d x_{1} d y_{1} \\
M_{c f}=\iint_{A_{1}}-\left[\tau x_{1}, y_{1}-\frac{|U|}{U} \mu_{f} p_{c}\left(x_{1}, y_{1}\right)\right] . \\
w d x_{1} d y_{1}+\iint_{A_{2}}\left[\tau x_{1}, y_{1}-\frac{|U|}{U} \mu_{f} p_{c}\left(x_{1}, y_{1}\right)\right] \cdot w d x_{1} d y_{1}
\end{gathered}
$$

where $A_{1}$ is the nominal contact area of the crosshead slipper-guide plate on the thrust side, and $A_{2}$ is the nominal contact area of the crosshead slipper-guide plate on the anti-thrust side. In addition, $w$ is the distance between the crosshead slipper guide surface to the crosshead pin center, as shown in Fig. 4(a), $\mu_{f}$ is the friction coefficient of the asperity contact, and $\tau$ is the fluid shear stress on the crosshead slipper and can be described as follows [44]:

$$
\tau=-\frac{\mu U}{h_{c}}\left(\varphi_{f}+\varphi_{f s}\right)-\phi_{f p} \frac{h_{c}}{2} \frac{\partial p}{\partial y_{1}}
$$

where $\phi_{f}, \phi_{f s}$, and $\phi_{f p}$ are the shear stress factors. The calculation method is based on Patir and Cheng's approach [33].

The change in the lubricating oil temperature when the crosshead slipper is located at different locations of the guide is ignored because the ambient temperature of the slipper-guide system is constant. In addition, the temperature increase of the lubricating oil during the startup process has not been considered because the lubricating system continuously supplies the crosshead slipper with a constant-temperature lubricant, and there is no fuel ignition during the startup process.

It should be noted that the calculations of the flow factors and the contact factor in the average Reynolds equation assume that the surface roughness height obeys a Gaussian distribution. In fact, engineering surfaces usually have a non-Gaussian topography. In addition, the influences of the elastic deformation, inter-asperity cavitation, and lubricant thermal effects on the flow factors were not considered in the current study for simplicity. Meng et al. discussed these issues in depth in their previous study. They found that these influencing factors should be considered over the range of low film thickness to roughness ratio. In addition, a simple method for calculating the contact factor for non-Gaussian surfaces is also presented. Interested readers can refer to the relevant studies [45-48].

\section{Numerical simulation method}

In the current study, the newly presented multi-body tribo-dynamic model of low-speed marine diesel engines during engine startup consists of four second- 
order ordinary differential equations. To facilitate these numerical solutions, they are transformed into eight equivalent first-order nonlinear ordinary differential equations. The eight equations can be written in the following general form:

$$
y^{\prime}=f(t, y)
$$

where $y=\left(\mathrm{e}_{\mathrm{t}}, \mathrm{e}_{\mathrm{b}}, \mathrm{e}_{\mathrm{tp}}, \varphi, \dot{\mathrm{e}}_{\mathrm{t}}, \dot{\mathrm{e}}_{\mathrm{b}}, \dot{\mathrm{e}}_{\mathrm{tp}}, \dot{\varphi}\right)^{T}$.

The modified extended backward differentiation formula (MEBDF) method [49, 50], which has been proven to be efficient in solving the tribo-dynamic model [51], is used in the current study to solve the first-order ordinary differential equations. Once the values of functions $\boldsymbol{y}_{n}, \boldsymbol{y}_{n+1}, \ldots . \boldsymbol{y}_{n+k-1}$ at the time steps $t_{n}, t_{n+1}, \ldots . t_{n+k-1}$ are obtained, the MEBDF method uses three steps to calculate $\boldsymbol{y}_{n+k}$, which represents the value of function $y$ at the next time step, the details of which can be found in previous studies $[4,12]$.

\section{Results}

Based on the tribo-dynamic model and numerical solution algorithm proposed in this paper, the triobodynamics of the crosshead slipper-guide friction pair during the startup process is simulated. For comparison, the tribo-dynamics under the rated conditions were also calculated. The rated rotation speed of the crankshaft was $159 \mathrm{rpm}$.

The main input parameters of a low-speed marine diesel engine are listed in Table 1 . The surface topography parameters of the crosshead slipper-guide system are presented in Table 2 . The asperity density $\eta$ and average asperity summit radius $\beta$ were chosen from a previous study [52]. The cylinder pressure in one cycle during the startup process and under the rated conditions is shown in Fig. 5. During the startup process, the high-pressure air valve opens when the piston moves downward. The high-pressure air replaces the gas to push the piston downward and accelerates the crankshaft. Therefore, the cylinder pressure within $0^{\circ}$ to $180^{\circ} \mathrm{CA}$ is approximately the same as highpressure air, as shown in Fig. 5. The exhaust valve opens during the upward movement of the piston. The air in the cylinder is exhausted, and the pressure in the cylinder within $180^{\circ}$ to $360^{\circ} \mathrm{CA}$ is approximately the exhaust pipe pressure, as shown in Fig. 5.

The starting speed of the marine diesel engine considered in this study is approximately $50 \mathrm{rpm}$. When the crankshaft reaches the starting speed, the

Table 1 Basic parameters for the low-speed marine diesel engine.

\begin{tabular}{|c|c|c|}
\hline Parameter & Meaning & Value \\
\hline$I_{c}$ & $\begin{array}{l}\text { Rotary inertia of crosshead slipper } \\
\text { about its COM }\end{array}$ & $0.83\left(\mathrm{~kg} \cdot \mathrm{m}^{2}\right)$ \\
\hline$I_{\mathrm{cp}}$ & $\begin{array}{c}\text { Rotary inertia of crosshead pin } \\
\text { about its COM }\end{array}$ & $0.51\left(\mathrm{~kg} \cdot \mathrm{m}^{2}\right)$ \\
\hline$I_{\mathrm{p}}$ & $\begin{array}{c}\text { Rotary inertia of piston about its } \\
\text { COM }\end{array}$ & $1.11\left(\mathrm{~kg} \cdot \mathrm{m}^{2}\right)$ \\
\hline$I_{\text {rod }}$ & $\begin{array}{l}\text { Rotary inertia of piston rod about } \\
\text { its COM }\end{array}$ & $52.36\left(\mathrm{~kg} \cdot \mathrm{m}^{2}\right)$ \\
\hline$I_{\mathrm{cr}}$ & $\begin{array}{c}\text { Rotary inertia of connecting rod } \\
\text { about its COM }\end{array}$ & $258.50\left(\mathrm{~kg} \cdot \mathrm{m}^{2}\right)$ \\
\hline$L$ & Length of piston rod & $2074 \mathrm{E}-3(\mathrm{~m})$ \\
\hline$L_{1}$ & $\begin{array}{l}\text { Vertical distance between COM of } \\
\text { piston and top end of piston skirt }\end{array}$ & $29.50 \mathrm{E}-3(\mathrm{~m})$ \\
\hline$L_{2}$ & $\begin{array}{l}\text { Vertical distance between COM of } \\
\text { piston and bottom end of piston skirt }\end{array}$ & $29.50 \mathrm{E}-3(\mathrm{~m})$ \\
\hline$L_{3}$ & Length of crosshead slipper & 300E-3 (m) \\
\hline$l_{r t}$ & Length of connecting rod & $1600 \mathrm{E}-3(\mathrm{~m})$ \\
\hline$m_{\mathrm{c}}$ & Mass of crosshead slipper & $25(\mathrm{~kg})$ \\
\hline$m_{\mathrm{cp}}$ & Mass of crosshead pin & $60(\mathrm{~kg})$ \\
\hline$m_{\mathrm{p}}$ & Mass of piston & $90(\mathrm{~kg})$ \\
\hline$m_{\text {rod }}$ & Mass of piston rod & $202.80(\mathrm{~kg})$ \\
\hline$m_{\mathrm{cr}}$ & Mass of connecting rod & $575.60(\mathrm{~kg})$ \\
\hline$R$ & Piston radius & $170 \mathrm{E}-3(\mathrm{~m})$ \\
\hline$R_{\mathrm{c}}$ & Crank radius & $800 \mathrm{E}-3(\mathrm{~m})$ \\
\hline$R_{\text {pin }}$ & Crosshead pin radius & $130 \mathrm{E}-3(\mathrm{~m})$ \\
\hline$w$ & Half of the height of slipper & $325 \mathrm{E}-3(\mathrm{~m})$ \\
\hline$J$ & Rotation inertia of the crankshaft & $8 \mathrm{E} 4\left(\mathrm{~kg} \cdot \mathrm{m}^{2}\right)$ \\
\hline$M$ & Resistance moment on the shaft & $1000(\mathrm{~N} \cdot \mathrm{m})$ \\
\hline
\end{tabular}

COM: Center of mass

Table 2 Crosshead slipper-guide system surface topography.

\begin{tabular}{cc}
\hline Parameter & Value \\
\hline Surface pattern parameter & 1 \\
Guide surface rms roughness & $0.7(\mu \mathrm{m})$ \\
Crosshead slipper surface rms roughness & $0.8(\mu \mathrm{m}$ \\
$\eta$ & $0.038\left(\mu \mathrm{m}^{-2}\right)$ \\
$\beta$ & $7.57(\mu \mathrm{m})$ \\
Asperity friction coefficient $\left(\mu_{f}\right)$ & 0.15 \\
\hline
\end{tabular}




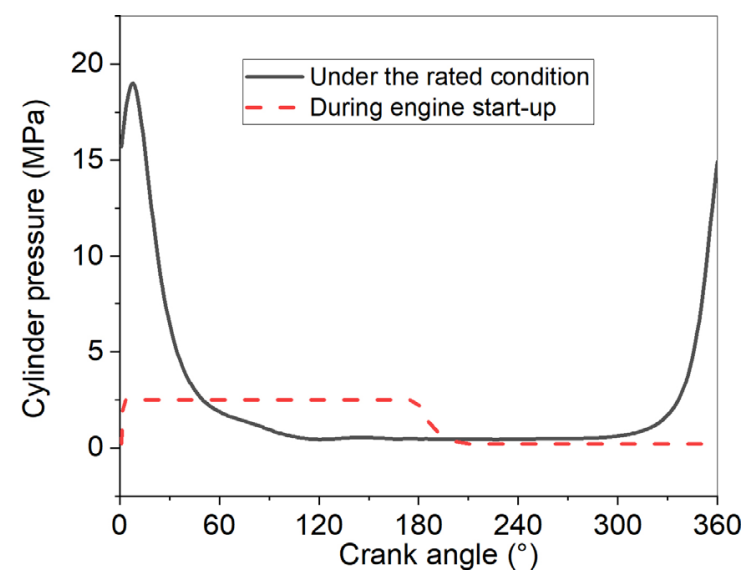

Fig. 5 Cylinder pressure of the engine in one cycle when operating during the startup process and under the rated conditions.

compressed air is disengaged, and the fuel is injected into the combustion chamber. The crankshaft will reach the rated speed quickly under high-pressure gas in the combustion chamber. Owing to the short duration of this transition phase and the lack of relevant experimental cylinder pressure data, this issue is not discussed in the current study.

The nominal contact area of the crosshead slipperguide is $300 \mathrm{~mm} \times 40 \mathrm{~mm}$, the lubricating oil temperature is $80^{\circ} \mathrm{C}$, the slipper-guide clearance is $200 \mu \mathrm{m}$, and the profile of the slipper is symmetrical. Each of the following sections will change one of the above parameters to explore its effect on the tribo-dynamic performance of the crosshead slipper.

\subsection{Effect of lubricating oil temperature}

In this section, the effect of the lubricating oil temperature on the tribo-dynamics of the crosshead slipper is discussed. Figure 6(a) shows the friction loss of the crosshead slipper during the engine startup process. It can be seen that as the startup process proceeds, the friction loss of the crosshead slipper gradually decreases. This is because, as the crankshaft rotation speed increases during the startup process (as shown in Fig. 7), the hydrodynamic effect of the lubricant increases and the asperity contact force of the crosshead slipper decreases. As a result, the friction loss of the crosshead slipper decreases. As shown in Fig. 6(a), as the lubricant temperature increases, the friction loss significantly increases during the startup process.
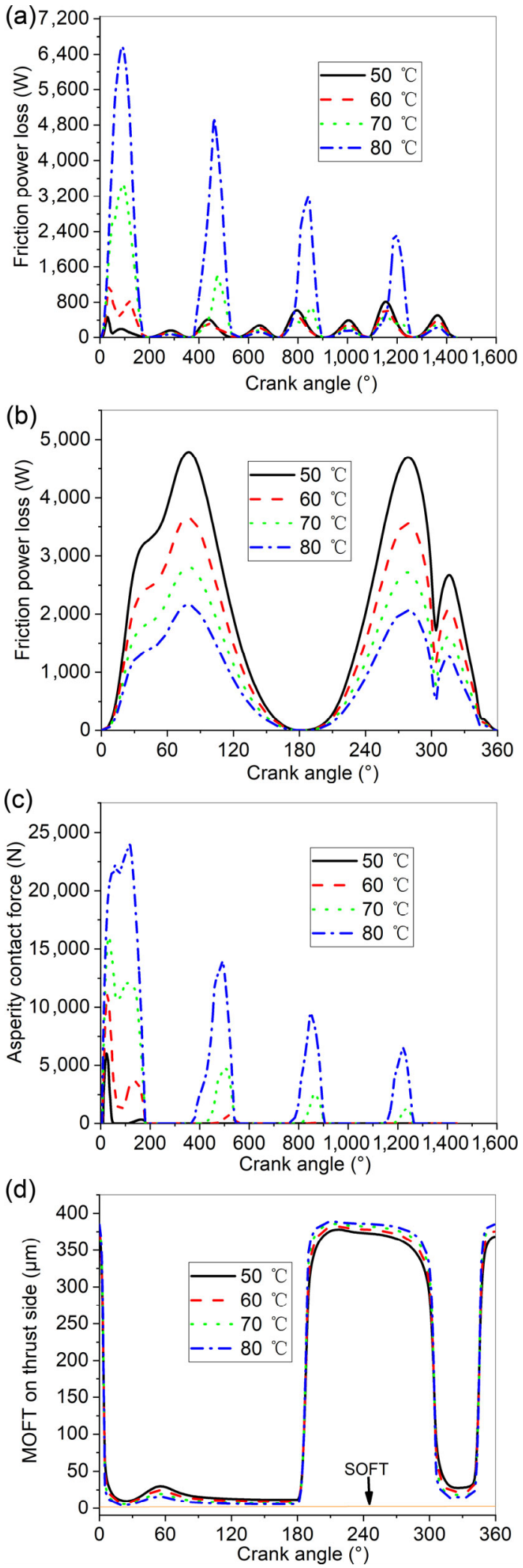

Fig. 6 Effect of lubricating oil temperature: (a) friction power loss during startup, (b) friction power loss under the rated conditions, (c) asperity contact force during startup, and (d) MOFT under the rated conditions. 
By contrast, under the rated conditions, increasing the oil temperature will significantly reduce the friction losses, as shown in Fig. 6(b). The reason for this difference can be found by comparing Figs. 6(c) and 6(d). It can be seen that, during the startup process, an asperity contact occurs between the crosshead slipper and guide because of the insufficient oil-film carrying capacity. As the lubricant temperature increases, the oil-film carrying capacity decreases further, and the asperity contact phenomenon intensifies, which results in a significant friction loss (as shown in Fig. 6(c)). In comparison, under the rated conditions, the crosshead slipper moves at a higher speed; thus, the hydrodynamic effect is noticeable. The minimum oil film thickness (MOFT) is still larger than the safe oil film thickness (SOFT) when the lubricating oil is heated to $80^{\circ} \mathrm{C}$. Therefore, no asperity contact occurs, and the fluid shear stress causes friction of the crosshead slipper under the rated conditions. As the lubricant temperature increases, the viscosity of the oil film decreases and the fluid shear stress decreases.

Figure 7 shows the crankshaft rotation speed during the startup process. As the startup progresses, the rotational speed of the crankshaft can reach the starting speed under the action of high-pressure air, as shown in Fig. 7. It can be seen that a higher lubricating oil temperature results in a slightly lower crankshaft speed at the same moment. From the above analysis, it is not difficult to infer that this is mainly due to the larger friction of the crosshead slipper.

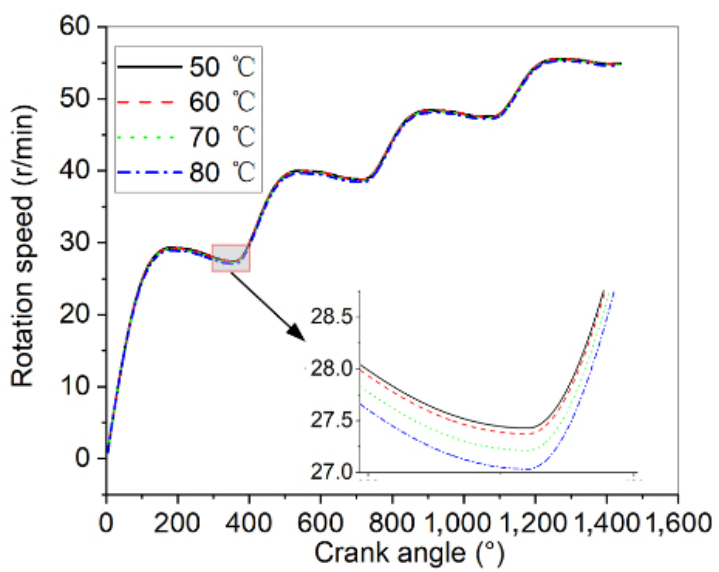

Fig. 7 Details of crankshaft rotation speed during the startup process.
The maximum transverse velocity of the center of the crosshead slipper in different cycles during the startup process, and the maximum transverse velocity of the crosshead slipper center in one cycle under the rated conditions are shown in Fig. 8. It can be seen that as the startup process proceeds, the transverse velocity of the crosshead slipper increases. This is mainly caused by the increase in the crankshaft rotation speed. However, the amplitude of the maximum transverse velocity is smaller than that under the rated conditions, as shown in Fig. 8(b). Figure 8 shows that a higher lubricating oil temperature results in a larger transverse velocity of the crosshead slipper, which is suitable for both the startup and rated conditions.

Figure 9 focuses on the changes in the asperity contact pressure field and oil film pressure field of the crosshead slipper during the startup process. Four moments are selected, i.e., $100^{\circ}, 460^{\circ}, 820^{\circ}$, and $1,180^{\circ} \mathrm{CA}$, and the crankshaft rotation speeds continue increasing from $100^{\circ}$ to $1,180^{\circ} \mathrm{CA}$, i.e., $24.5,36.5,45.6$, and $47.2 \mathrm{rpm}$, respectively. It can be seen from Fig. 9(a) that the oil film pressure increases from $100^{\circ}$ to $1,180^{\circ} \mathrm{CA}$, which is not difficult to understand; the
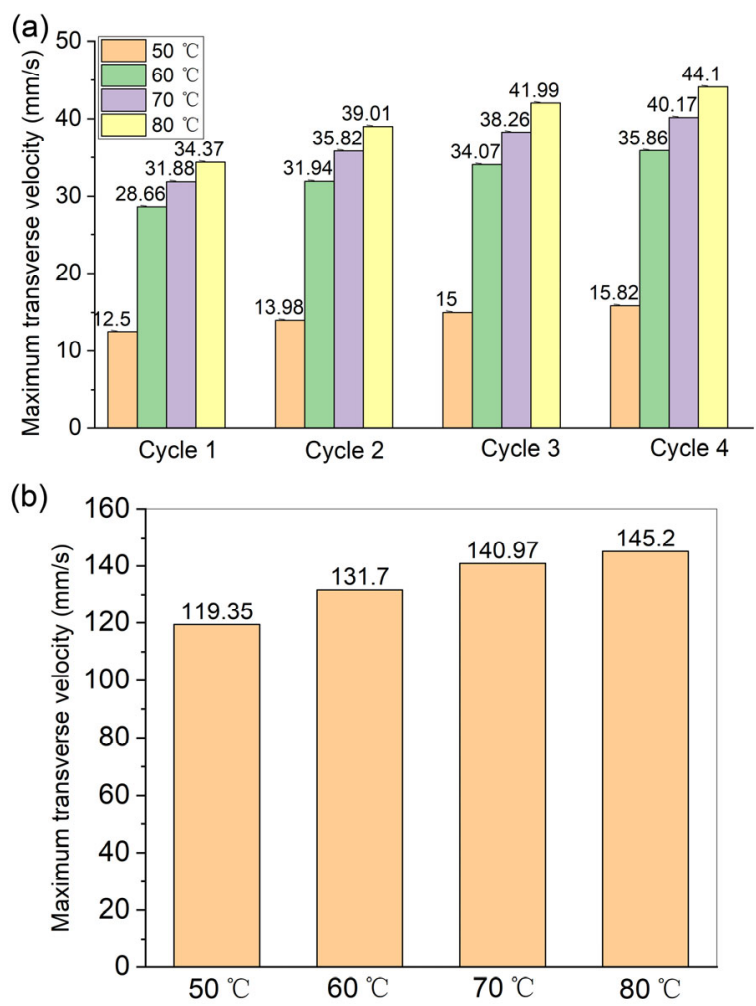

Fig. 8 Maximum transverse velocity of crosshead slipper center during (a) startup process and (b) rated conditions. 
(a)
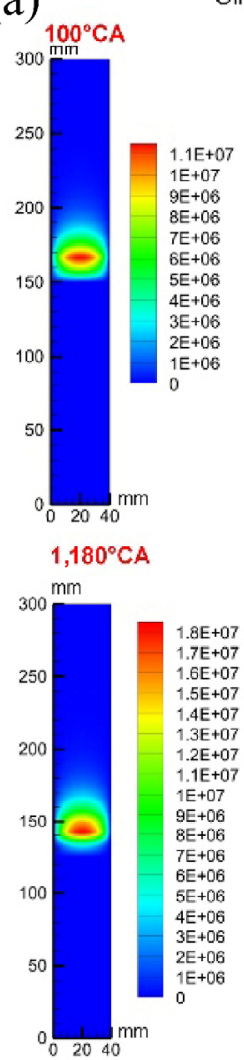

Oil film pressure

(Pa)
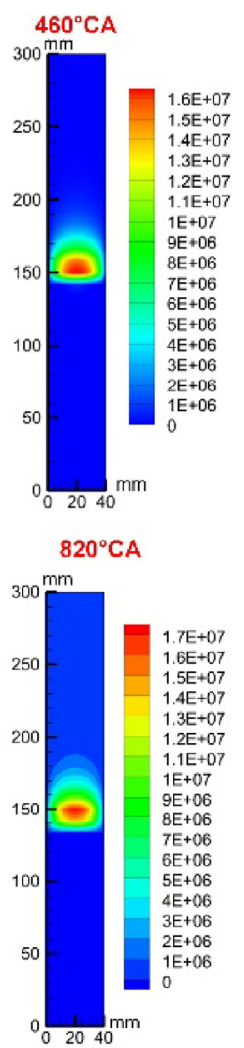

(b)

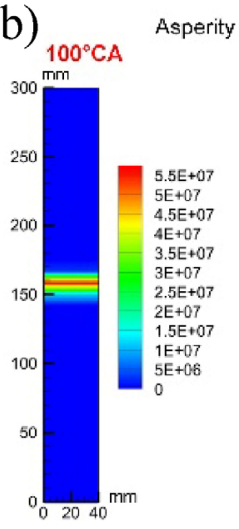

$1,180^{\circ} \mathrm{CA}$

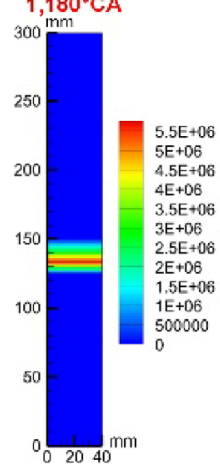

Fig. 9 Oil film pressure and asperity contact pressure during the startup process: (a) lubricant oil pressure and (b) asperity contact pressure. velocity of the crosshead slipper increases and the hydrodynamic effect is enhanced as the crankshaft rotation speed increases. By contrast, as shown in Fig. 9(b), the asperity contact pressure is continuously weakened because the oil film force gradually balances the load of the crosshead slipper. The change also corresponds to the change in the friction loss shown in Fig. 6(a).

The calculation results described in this section initially show that the startup and rated conditions are extremely different. The heating temperature of the lubricating oil under the rated conditions $\left(80^{\circ} \mathrm{C}\right.$ for the engine in the current study) is unsuitable for the startup condition. The lubricating oil temperature during startup must not be excessively high.

\subsection{Effect of nominal contact area of crosshead slipper-guide}

Under the rated conditions, reducing the crosshead slipper-guide nominal contact area is an effective method for reducing the friction loss of the engine [30]. However, the effect of this measure during the startup process is unclear, and is therefore explored in this section. Figure 10(a) shows that with the decrease in the nominal contact area, the friction loss increases significantly. However, the same approach significantly reduces the friction loss under the rated conditions, as shown in Fig. 10(b), which is consistent with the previous study [30].

The oil film bearing area of the crosshead slipper is reduced owing to the decrease in the nominal area, which increases the severity of the asperity contact of the crosshead slipper during engine startup, as shown in Fig. 10(c). The friction loss thus increases significantly. Figure 10(d) shows that, as the startup process proceeds, the fluid friction continues to increase owing to the increased longitudinal velocity of the crosshead slipper. However, the asperity friction still plays a dominant role.

Figure 11(a) shows the maximum transverse velocity of the crosshead slipper center in four cycles during the startup, and Fig. 11(b) shows the maximum transverse velocity of the crosshead slipper center in one cycle under the rated conditions. It can be seen that, as the startup process proceeds, the maximum transverse velocity of the crosshead slipper tends to 

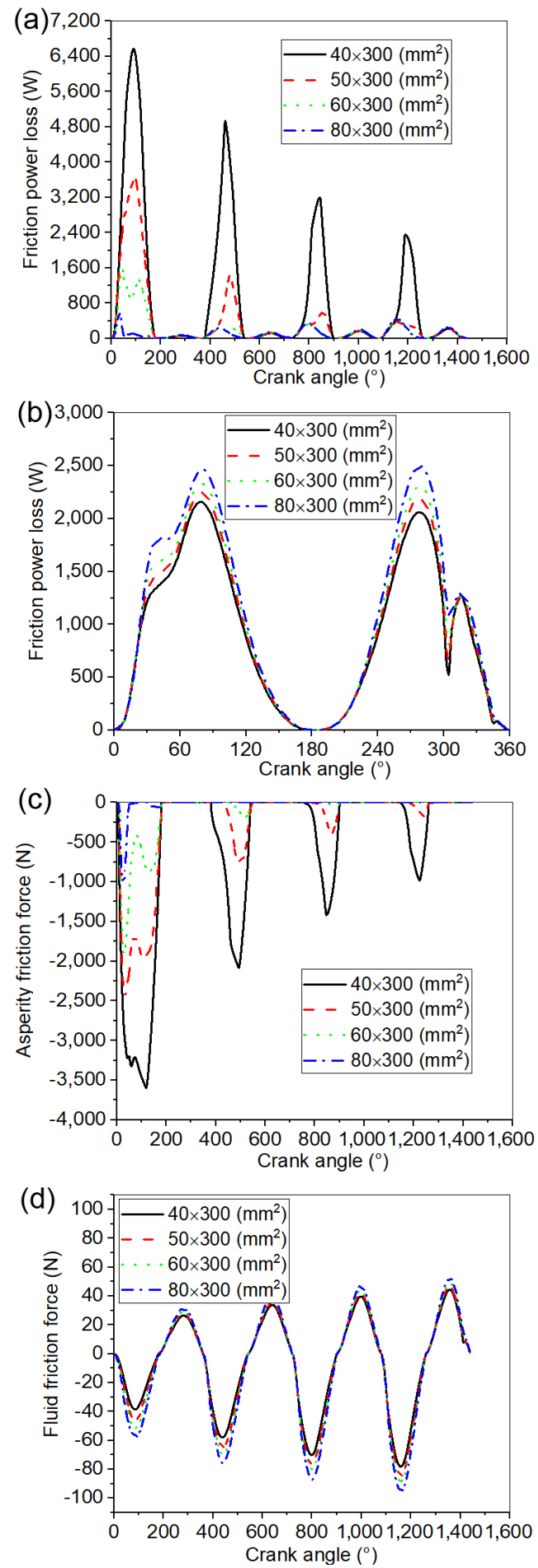

Fig. 10 Effect of the nominal contact area: (a) friction power loss during the startup process, (b) friction power loss under the rated conditions, (c) asperity friction force during the startup process, and (d) fluid friction force during the startup process.

increase, although the amplitude is smaller than that under the rated conditions, as shown in Fig. 11(b). From Figs. 11(a) and 11(b), it can be concluded that

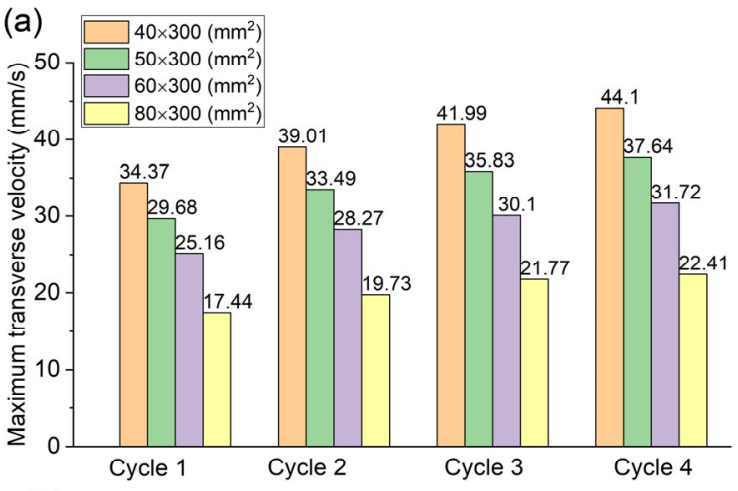

(b)

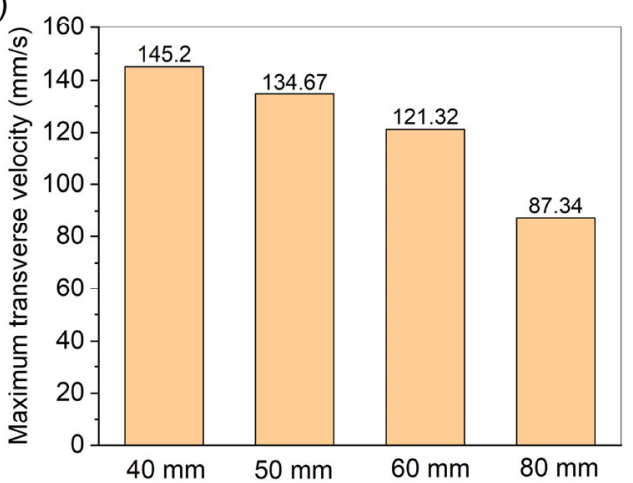

Fig. 11 Maximum transverse velocity of crosshead slipper center during the (a) startup process and (b) under the rated conditions.

the reduction of the nominal contact area will cause the transverse velocity of the crosshead slipper to increase during the engine startup and under the rated conditions.

The discussion in this section shows that reducing the nominal area to reduce the friction loss of the crosshead slipper under the rated conditions may cause a more severe asperity contact during the engine startup process, resulting in a greater friction loss.

\subsection{Effect of nominal clearance of crosshead slipper- guide}

This section discusses the effect of the nominal clearance of the crosshead slipper-guide on the tribo-dynamic performance of the crosshead slipper during the engine startup process. For comparison, the situation under the rated conditions was also demonstrated. It can be seen from Fig. 12(a) that, as the nominal clearance increases, the friction loss during the startup process significantly increases, which is extremely different from the situation under the rated conditions, as shown in Fig. 12(b). Under the rated conditions, the friction loss decreases as the nominal clearance increases. 

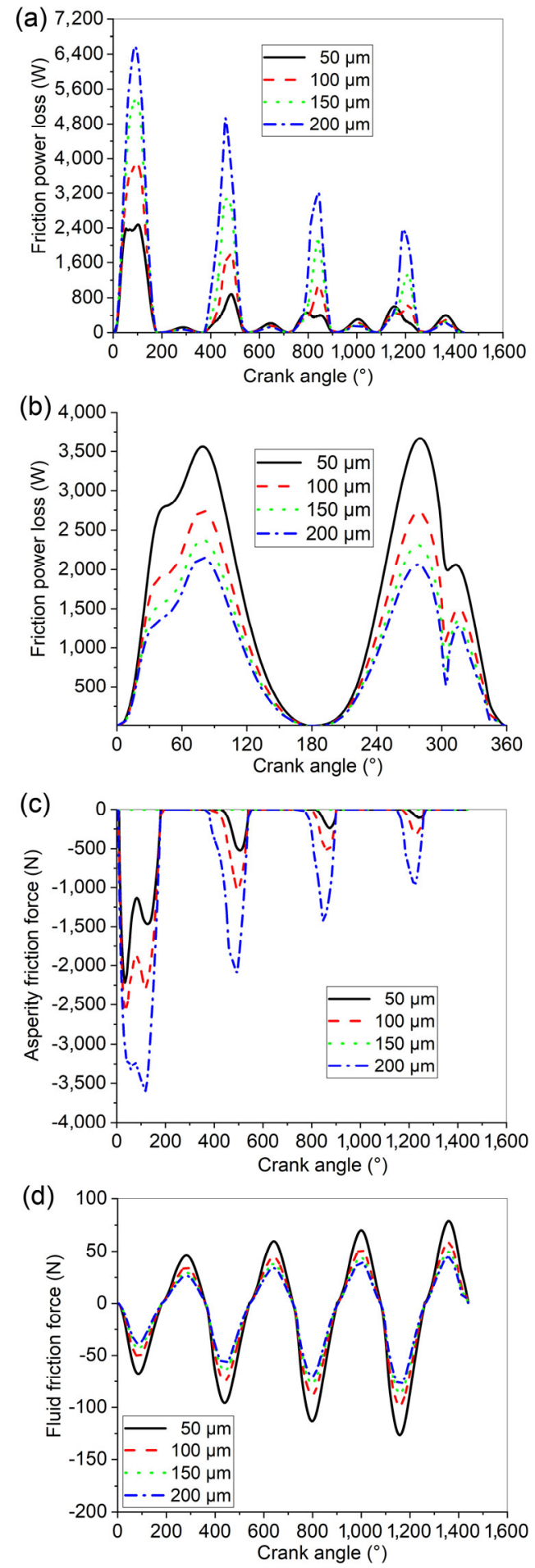

Fig. 12 Effect of the crosshead slipper-guide nominal clearance: (a) friction power loss during the startup process, (b) friction power loss under the rated conditions, (c) asperity friction force during the startup process, and (d) fluid friction force during the startup process.

The reasons for this difference can be described as follows. During the startup process, the friction is mainly caused by the asperity contact, which will be exacerbated by the increase in the nominal clearance between the crosshead slipper and the guide, as shown in Fig. 12(c). Under the rated conditions, the friction force is caused by the fluid shear stress, and the increase in clearance reduces the fluid shear stress, as shown in Eq. (36). Figure 12(d) shows the change in fluid friction of the crosshead slipper during the startup process. It can be seen that as the startup process proceeds, the fluid friction continues to increase. At the same time, a larger nominal clearance results in less fluid friction.

Figures 13(a) and 13(b) compare the transverse displacement of the crosshead slipper during the startup process and under the rated conditions. It can be seen that the increase in the nominal clearance between the crosshead slipper and the guide results in a larger secondary motion of the crosshead slipper. This makes the crosshead slipper closer to the guide at certain moments, thereby increasing the risk of asperity contact. A schematic diagram of this phenomenon is shown in Fig. 14. Figure 15 shows the MOFT on the thrust side during the startup. During the expansion stroke, the MOFT is reduced with an increase in the nominal clearance, as shown in Fig. 15(b). The asperity contact is increased as a result, corresponding to the results shown in Fig. 12(c).

Figure 13(c) shows the maximum transverse velocity of the crosshead slipper center in four cycles during the startup. Figure 13(d) shows the maximum transverse velocity of the crosshead slipper center in one cycle under the rated conditions. It can be seen that a larger nominal clearance will cause a larger transverse velocity of the crosshead slipper, which will increase the risk of an asperity contact. This risk is even more pronounced during the startup process, owing to an insufficient hydrodynamic effect.

\subsection{Effect of profile on crosshead slipper}

Machining a specific profile on the friction pair is an effective measure for improving the tribological performance $[12,53]$. The effects of three profiles were explored in the current study. As shown in Fig. 16, three types of quadratic profiles are assumed in the crosshead slipper. The profile heights are the same, but the positions of the convex points are different. 

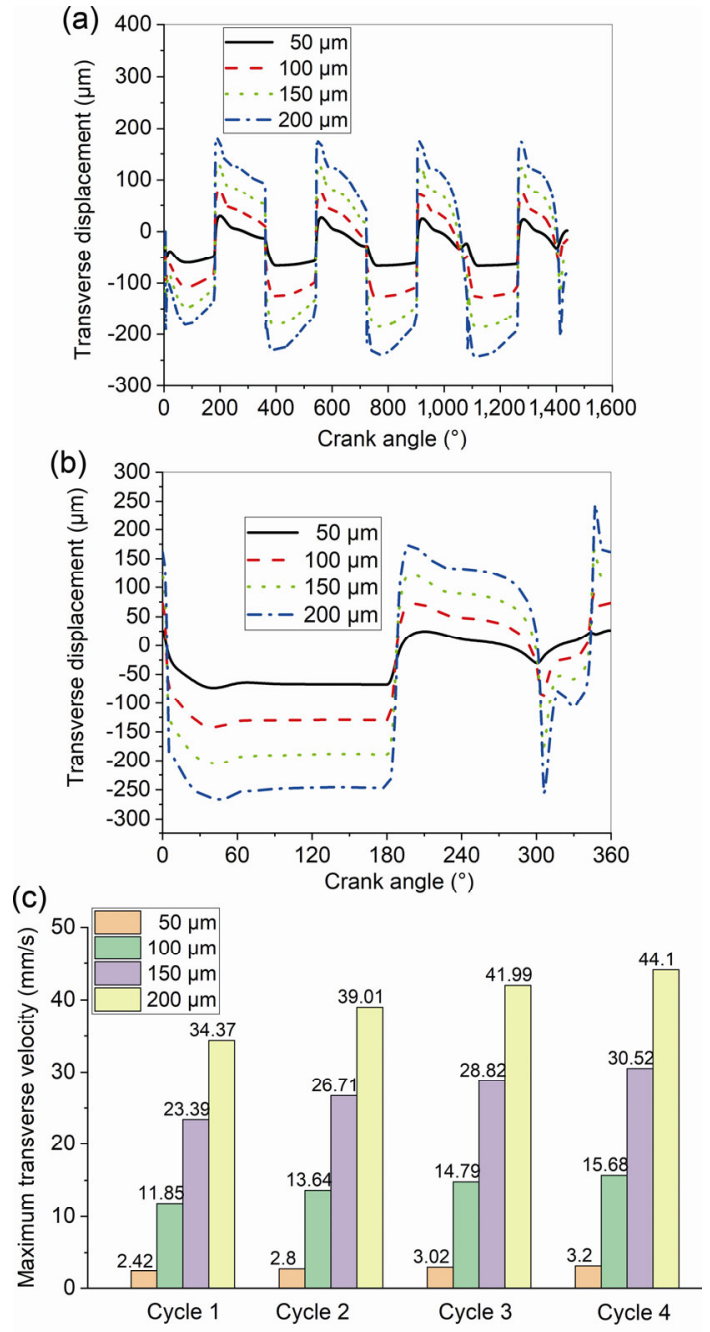

(d)

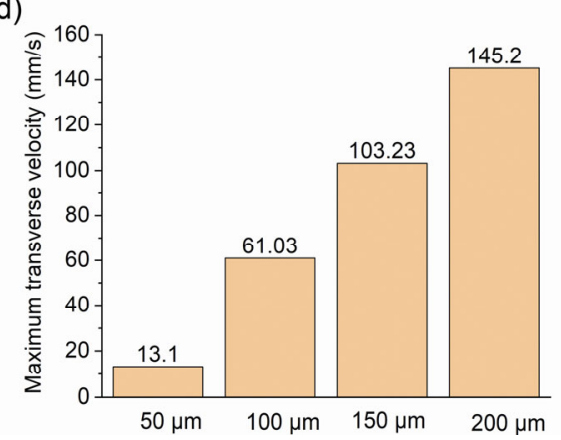

Fig. 13 Effect of the crosshead slipper-guide nominal clearance: (a) transverse displacement during the startup, (b) transverse displacement under the rated conditions, (c) maximum transverse velocity of the crosshead slipper center during the startup, and (d) maximum transverse velocity of the crosshead slipper center under the rated conditions.

It can be seen from Fig. 17(a) that, during the engine startup process, the symmetrical profile (Profile II) causes a considerable friction loss. However, under the rated conditions, this is a good choice, as shown (a)
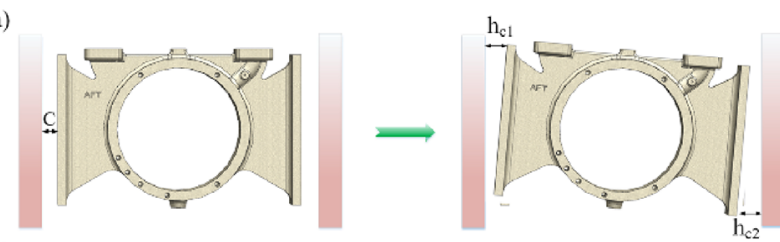

(b)
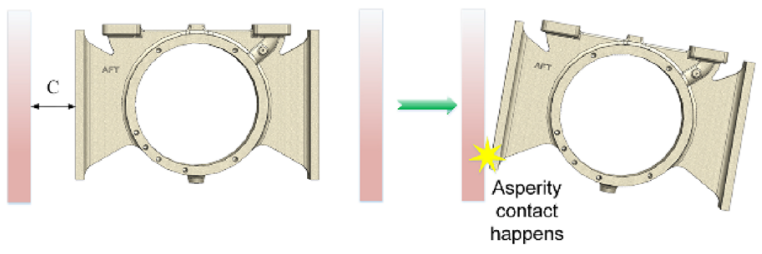

Fig. 14 Effect of nominal clearance on the secondary motion of the crosshead slipper: (a) small and (b) large nominal clearance.
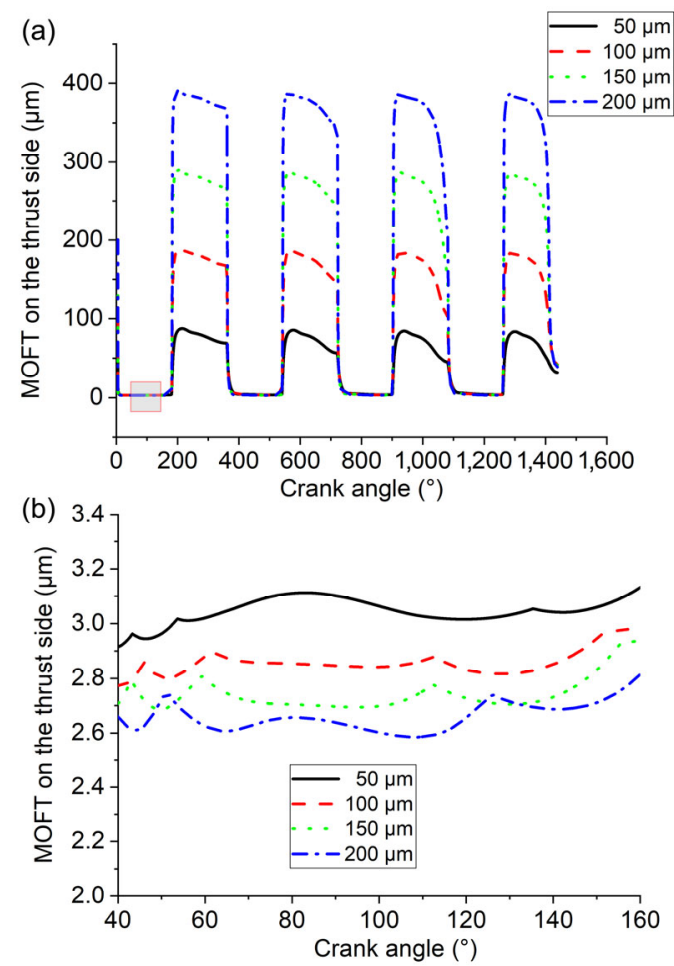

Fig. 15 MOFT of the crosshead slipper on the thrust side during the startup process: (a) MOFT and (b) an enlarged drawing.

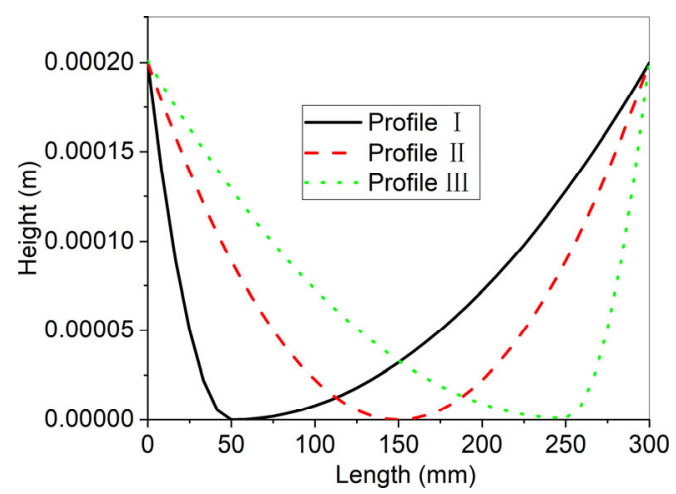

Fig. 16 Three types of profiles on the crosshead slipper. 


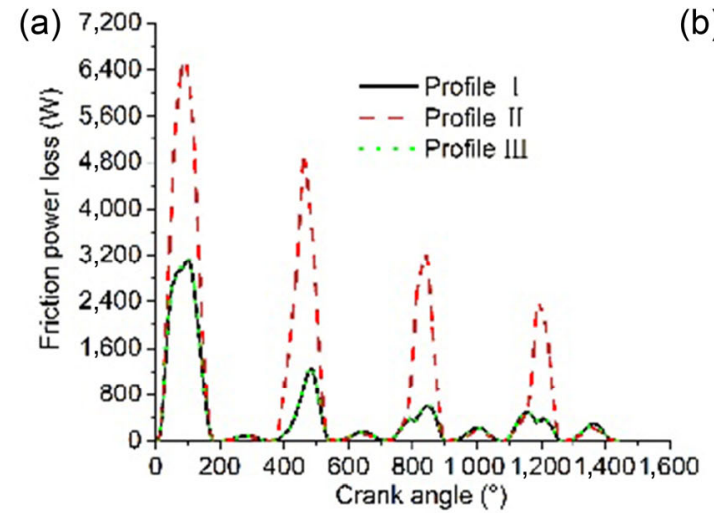

(b)

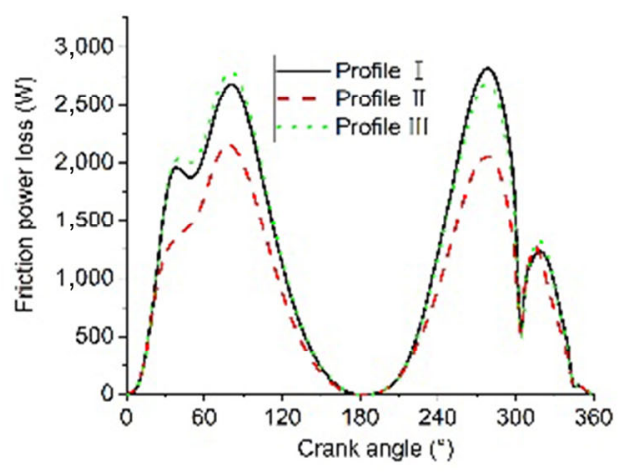

Fig. 17 Effect of the crosshead slipper profile: friction power loss (a) during the startup process and (b) under the rated conditions.

in Fig. 17(b), which is consistent with the results of a previous study [12]. These results prove again that the design requirements for the startup process conflict with the design requirements for the rated conditions.

Figure 18 shows the MOFT on the thrust side of the crosshead slipper during the engine startup process. It can be seen that, during the downward movement of the piston, the symmetrical profile leads to a smaller minimum oil film thickness, which makes the asperity contact more severe and results in a more significant friction loss, as shown in Fig. 17(a).

Figure 19 shows the oil film pressure field and the asperity contact pressure field when the startup reaches $100^{\circ} \mathrm{CA}$. It can be seen that the asperity contact of the crosshead slipper with the symmetrical profile is indeed more serious at this moment, and the lubrication area is smaller. The other two types of profiles have a larger oil film lubrication zone and a smaller asperity contact pressure.

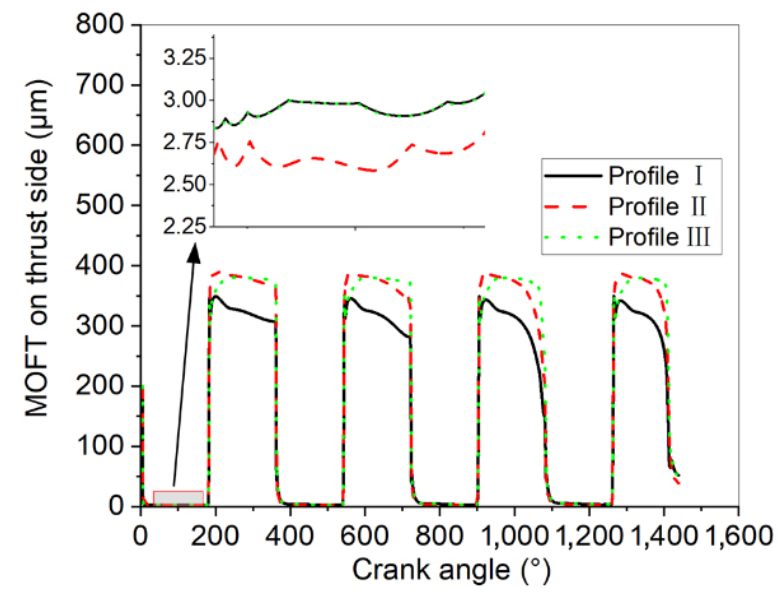

Fig. 18 Minimum oil film thickness (MOFT) on the thrust side.

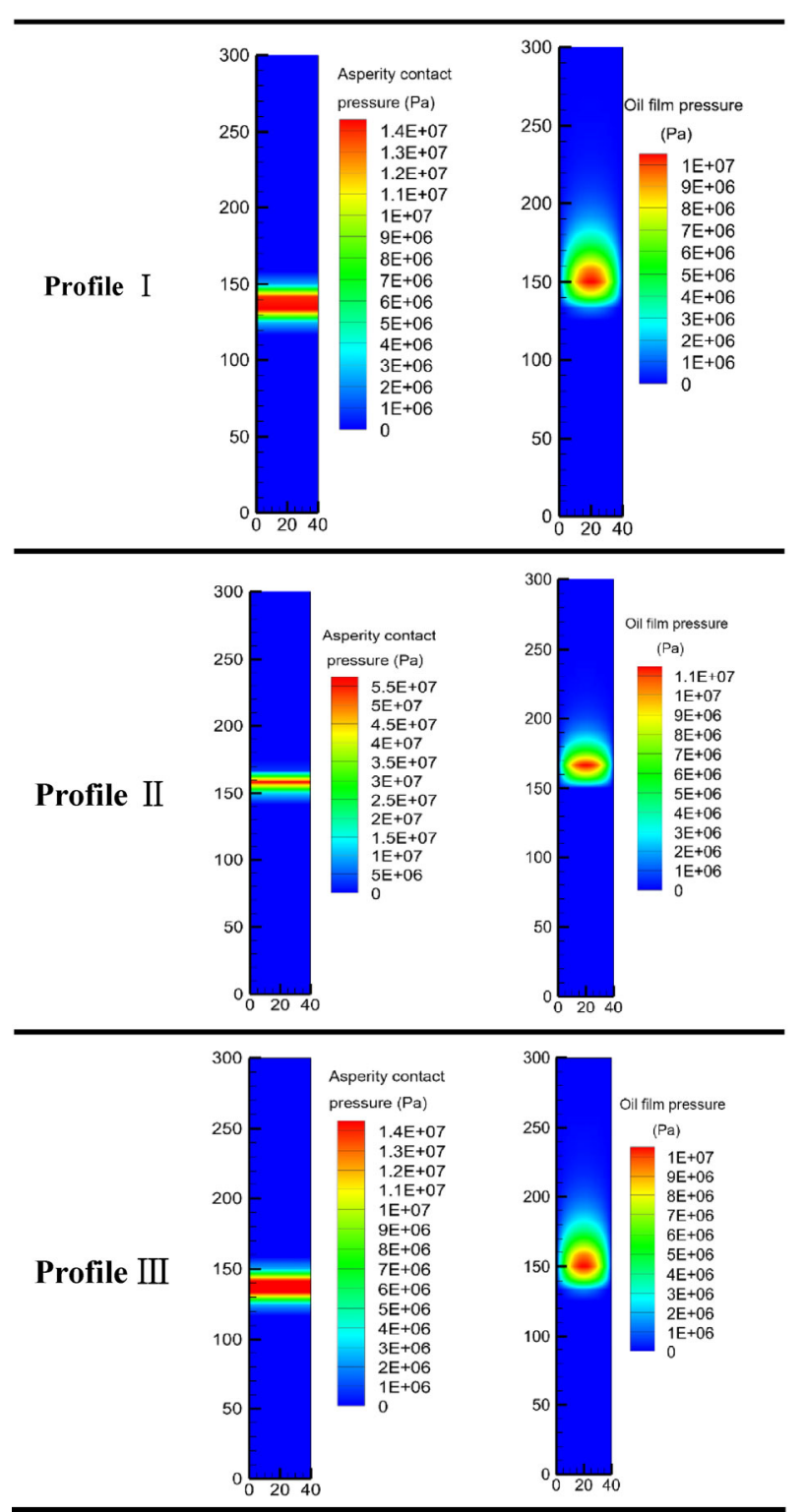

Fig. 19 Oil film pressure field and asperity contact pressure field when the startup reaches $100^{\circ} \mathrm{CA}$. 
From the calculation results presented above, it can be seen that some measures (increasing the lubricant temperature, decreasing the nominal contact area, increasing the nominal clearance, and using the symmetrical profile), which are beneficial for the low friction of the crosshead slipper guide under the rated conditions, may significantly increase the asperity contact and wear of the crosshead slipper during the startup process. The choice of these design parameters is contradictory during the two stages. Therefore, we should comprehensively consider and choose a compromise plan during the design stage. Regarding the parameters involved in the current study, we believe there are two ways to solve this problem under such a background.

\section{(1) Different lubricant temperatures during different stages}

From the current study, properly reducing the lubricating oil temperature during the startup process and then increasing the lubricant temperature after the rotation speed increases is a good approach. In other words, the lubricating oil temperature should be controlled at different values during these two stages. In this way, the asperity contact of the crosshead slipper during the startup process can be reduced, and the friction loss under the rated conditions can also be reduced. For example, during the startup process, the lubricating oil can be controlled to $50{ }^{\circ} \mathrm{C}$, and the lubricating oil is then heated to $80^{\circ} \mathrm{C}$ under the rated conditions.

\section{(2) Multi-objective optimal design}

For the choice of the nominal crosshead slipper-guide area, crosshead slipper profile, and nominal clearance, a multi-objective optimization design method can be used. For example, we can choose the friction loss under the rated conditions and the wear volume during the startup process as the two optimization objectives, and then find a compromised design plan. The design plan should make both the wear volume during the startup process and the friction loss under the rated conditions satisfactory. For example, the multi-objective optimization design based on the orthogonal experiment method seems to be a suitable choice. The details of this method can be found in the relevant literature $[54,55]$.

\section{Conclusions}

This paper presented a new tribo-dynamic model for low-speed marine engines during the engine startup process. The tribo-dynamic performance of the crosshead slipper-guide friction pair during the startup process was analyzed and compared with those under the rated conditions. The results show that the tribodynamics of the crosshead slipper during the startup process is quite different than that under the rated conditions. A higher lubricating oil temperature, smaller crosshead slipper-guide nominal contact area, and larger clearance between the crosshead slipper and the guide aggravates the asperity contact force and increases the friction loss of the crosshead slipper during the startup process. However, a good effect in reducing the friction loss can be obtained when these measures are used under the rated conditions. The specific conclusions are as follows.

1) The asperity contact mainly causes friction in the crosshead slipper during the engine startup. Increasing the oil temperature reduces the bearing capacity of the lubricant, resulting in a more intense asperity contact and larger friction loss. At the same time, a higher lubricant oil temperature increases the secondary motion of the crosshead slipper, which is found during both the startup process and under the rated conditions.

2) Decreasing the nominal contact area between the crosshead slipper and guide leads to an increase in the asperity contact during the engine startup, which will increase the wear and friction losses. As the nominal area decreases, the transverse movement of the crosshead slipper significantly increases.

3) Increasing the clearance between the crosshead slipper and the guide results in a more violent secondary motion, which causes a more intense asperity contact during the startup process. The friction loss increases as a result.

4) The symmetrical profile of the crosshead slipper can reduce the friction loss under the rated conditions. However, during the startup process, the offset profile seems to have a better effect on reducing the friction loss.

\section{Acknowledgements}

This study was supported by the Research Project 
of High Technological Vessels: Development of Low Speed Marine Engines (Grant No. MC-201501-D01-03), and the National Natural Science Foundation of China (Grant No. 51875344). Professor Youbai Xie, the leader of our group, contributed significantly to this research, but preferred not to be named as an author because he had no time available to check the details of the manuscript. The authors would like to express their sincere appreciation to Professor Xie for his help.

\section{Appendix}

A1 Dynamic equations of piston-piston rodcrosshead pin system, crosshead slipper, and connecting rod

Piston:

$$
\begin{gathered}
F_{\mathrm{p}}+F_{\mathrm{ip} 2}+F_{x 1}=0 \\
F_{\mathrm{g}}+F_{\mathrm{pf}}+F_{\mathrm{ip} 1}+G_{\mathrm{p}}+F_{y 1}=0 \\
M_{\mathrm{p}}+M_{\mathrm{pf}}+F_{\mathrm{ip} 2} \cdot\left(L_{2}+L+R_{\mathrm{pin}}\right)+F_{x 1} \cdot\left(L+R_{\mathrm{pin}}\right) \\
+M_{\mathrm{ip}}+M_{1}=0
\end{gathered}
$$

where $F_{\mathrm{g}}$ and $G_{\mathrm{p}}$ represent the gas force and piston gravity, respectively. In addition, $F_{\mathrm{p}}$ and $F_{\mathrm{pf}}$ are the normal and tangential forces of the piston skirt from the cylinder liner, respectively, which are obtained from the mixed lubrication analysis of the piston skirt-liner friction pair, and $M_{\mathrm{p}}$ and $M_{\mathrm{pf}}$ represent the moments of $F_{\mathrm{p}}$ and $F_{\mathrm{pf}}$ about the crosshead pin center, respectively. Moreover, $F_{x 1}, F_{y 1}$ and $M_{1}$ represent the restraining forces and restraining torque on the bottom of the piston, respectively, $R_{\text {pin }}$ is the radius of the crosshead pin, and $F_{\mathrm{ip} 1}$ and $F_{\mathrm{ip} 2}$ are the inertial forces of the piston in the longitudinal ( $Y$-direction) and transverse (X-direction) directions, respectively. Finally, $M_{i p}$ is the inertial moment of the piston. Piston rod:

$$
\begin{gathered}
F_{\text {irod2 }}-F_{x 1}+F_{x 2}=0 \\
F_{\text {irod } 1}+G_{\text {rod }}+F_{y 2}-F_{y 1}=0 \\
F_{\text {irod } 2} \cdot\left(\frac{L}{2}+R_{\text {pin }}\right)+M_{\text {irod }}-M_{1}-F_{x 1} \cdot\left(L+R_{\text {pin }}\right) \\
+M_{2}+F_{x 2} \cdot R_{\text {pin }}=0
\end{gathered}
$$

where $G_{\text {rod }}$ represents the gravity of the piston rod, and $F_{x 2}, F_{y 2}$ and $M_{2}$ are the restraining forces and restraining torque on the bottom of the piston rod due to the bolts, respectively. In addition, $F_{\text {irod1 }}$ and $F_{\text {irod2 }}$ are the inertial forces of the piston rod in the $X$ and $Y$-directions, respectively, while $M_{\text {irod }}$ represents the inertial moment of the piston rod.

Crosshead pin:

$$
\begin{gathered}
F_{\text {icp2 }}-2 \cdot F_{x}+F_{\text {crx }}-F_{x 2}=0 \\
F_{\text {icp1 }}-2 \cdot F_{y}+G_{\text {cp }}+F_{\text {cry }}-F_{y 2}=0 \\
M_{\text {icp }}-M_{2}-F_{x 2} \cdot R_{\text {pin }}=0
\end{gathered}
$$

where $G_{\mathrm{cp}}$ is the gravity of the crosshead pin, and $F_{\text {crx }}$ and $F_{\text {cry }}$ are the components of the connecting rod force to the crosshead pin in the $X$ - and $Y$-directions, respectively.

From the force analysis of the piston, piston rod, and crosshead pin, the following equations can be obtained through mathematical processing:

$$
\begin{gathered}
F_{\mathrm{p}}+F_{\mathrm{ip} 2}+F_{\mathrm{irod} 2}+F_{\mathrm{icp} 2}-2 \cdot F_{x}+F_{\mathrm{cr} x}=0 \\
F_{\mathrm{g}}+F_{\mathrm{pf}}+F_{\mathrm{ip} 1}+F_{\text {irod1 }}+F_{\mathrm{icp} 1}-2 \cdot F_{y}+m_{\mathrm{q}} g+F_{\mathrm{cr} y}=0 \\
M_{\mathrm{p}}+M_{\mathrm{pf}}+F_{\mathrm{ip} 2} \cdot\left(L_{2}+L+R_{\mathrm{pin}}\right)+F_{\text {irod2 } 2} \cdot\left(\frac{L}{2}+R_{\mathrm{pin}}\right)+M_{\mathrm{q}}=0
\end{gathered}
$$

The sums of mass $m_{\mathrm{q}}$ and the moment of the inertia $M_{\mathrm{q}}$ can be described as follows:

$$
\begin{gathered}
m_{\mathrm{q}}=m_{\mathrm{cp}}+m_{\mathrm{rod}}+m_{\mathrm{p}} \\
M_{\mathrm{q}}=M_{\mathrm{icp}}+M_{\mathrm{irod}}+M_{\mathrm{ip}}=-I_{\mathrm{q}} \cdot \ddot{\gamma}_{\mathrm{p}}
\end{gathered}
$$

where $m_{\mathrm{cp}}, m_{\mathrm{rod}}$, and $m_{\mathrm{p}}$ are the masses of the crosshead pin, piston rod, and piston, respectively. In addition, $M_{\mathrm{icp}}, M_{\mathrm{irod}}$, and $M_{\mathrm{ip}}$ are the inertia moments of the crosshead pin, piston rod, and piston, respectively, and $\gamma_{p}$ is the small rotation angle of the piston-piston rod-crosshead pin system, the calculation method of which can be found in previous studies $[4,12]$. Finally, $I_{\mathrm{q}}$ is the sum of the rotation inertia of the crosshead pin, piston rod, and piston:

$$
I_{\mathrm{q}}=I_{\mathrm{cp}}+I_{\text {rod }}+I_{\mathrm{p}}
$$

Crosshead slipper: 


$$
\begin{gathered}
F_{\mathrm{c}}+F_{\mathrm{ic} 2}+F_{x}=0 \\
F_{\mathrm{cf}}+G_{\mathrm{c}}+F_{\mathrm{ic} 1}+F_{y}=0 \\
M_{\mathrm{c}}+M_{\mathrm{cf}}+F_{\mathrm{ic} 2} \cdot(a-b)+M_{\mathrm{ic}}=0
\end{gathered}
$$

where $F_{\mathrm{c}}$ and $F_{\mathrm{cf}}$ are the normal and tangential forces of the crosshead slipper from the guide, which will be obtained from the mixed lubrication model of the crosshead slipper-guide friction pair. $M_{\mathrm{c}}$ and $M_{\mathrm{cf}}$ are the moments of $F_{\mathrm{c}}$ and $F_{\mathrm{cf}}$ about the crosshead pin center, respectively. $F_{\text {ic1 }}$ and $F_{\text {ic2 }}$ are the inertial forces of the crosshead slipper in the longitudinal and transverse directions, respectively, $M_{\mathrm{ic}}$ is the inertial moment.

Connecting rod:

$$
\begin{gathered}
F_{\mathrm{icr} x}+F_{\mathrm{cs} x 1}-F_{\mathrm{cr} x}=0 \\
F_{c s y 1}+F_{\mathrm{icry}}+G_{\mathrm{cr}}-F_{c r y}=0 \\
F_{c r x} l_{r s} \cos \theta-F_{c r y} l_{r s} \sin \theta+F_{c s x 1} l_{s t} \cos \theta-F_{c s y 1} l_{s t} \sin \theta+M_{\mathrm{icr}}=0
\end{gathered}
$$

where $F_{i c r x}$ and $F_{i c r y}$ are the inertial forces in the $X$ and $Y$-directions of the connecting rod, respectively, $M_{i c r}$ represents the inertial moment of the connecting rod, $\theta$ is the connecting rod angle, and $G_{\text {cr }}$ is the gravity of the connecting rod.

\section{A2 Intermediate variables in tribo-dynamic model}

$$
\begin{gathered}
A_{11}=2 m_{\mathrm{c}}\left(1-\frac{b}{L_{3}}\right)+m_{\mathrm{p}}\left(1-\frac{a}{L_{3}}\right)\left(1-\frac{L+R_{\mathrm{pin}}+L_{2}}{L_{1}+L_{2}+L+R_{\mathrm{pin}}}\right) \\
+m_{\mathrm{rod}}\left(1-\frac{a}{L_{3}}\right)\left(1-\frac{\frac{L}{2}+R_{\mathrm{pin}}}{L_{1}+L_{2}+L+R_{\mathrm{pin}}}\right)+m_{\mathrm{cp}}\left(1-\frac{a}{L_{3}}\right)-j Z_{6} \\
A_{12}=2 m_{\mathrm{c}} \frac{b}{L_{3}}+m_{\mathrm{p}} \frac{a}{L_{3}}\left(1-\frac{L+R_{\mathrm{pin}}+L_{2}}{L_{1}+L_{2}+L+R_{\mathrm{pin}}}\right) \\
+m_{\mathrm{rod}} \frac{a}{L_{3}}\left(1-\frac{\frac{L}{2}+R_{\mathrm{pin}}}{L_{1}+L_{2}+L+R_{\mathrm{pin}}}\right)+m_{\mathrm{cp}} \frac{a}{L_{3}}-j Z_{7} \\
A_{13}=m_{\mathrm{p}} \frac{L+R_{\mathrm{pin}}+L_{2}}{L_{1}+L_{2}+L+R_{\mathrm{pin}}}+m_{\mathrm{rod}} \frac{\frac{L}{2}+R_{\mathrm{pin}}}{L_{1}+L_{2}+L+R_{\mathrm{pin}}} \text { (A24) }
\end{gathered}
$$

$$
\begin{aligned}
A_{14}= & -I_{1}\left(2 m_{\mathrm{c}}+m_{\mathrm{p}}+m_{\mathrm{rod}}+m_{\mathrm{cp}}\right) \tan \theta-\frac{I_{c r} I_{4}}{l_{r t} \cos \theta} \\
& -j Z_{5}+Z_{9}(1-j) \tan \theta
\end{aligned}
$$

$$
\begin{gathered}
C_{\mathrm{F}}=2 F_{\mathrm{c}}+F_{\mathrm{p}}+\left(I_{2}+I_{3}\right) \dot{\varphi}^{2}\left(2 m_{\mathrm{c}}+m_{\mathrm{p}}+m_{\mathrm{rod}}+m_{\mathrm{cp}}\right) \tan \theta \\
-\tan \theta\left(2 F_{\mathrm{cf}}+2 m_{\mathrm{c}} g+F_{\mathrm{g}}+F_{\mathrm{pf}}+m_{\mathrm{q}} g\right)+\frac{I_{\mathrm{cr}} I_{5} \dot{\varphi}^{2}}{l_{\mathrm{rt}} \cos \theta} \\
+j Z_{8}-\left(m_{\mathrm{cr}} g+Z_{10}\right) \cdot(1-j) \tan \theta \\
A_{21}=m_{\mathrm{c}}\left(1-\frac{b}{L_{3}}\right)(a-b)+\frac{I_{\mathrm{c}}}{L_{3}} \\
A_{22}=m_{\mathrm{c}} \frac{b}{L_{3}}(a-b)-\frac{I_{\mathrm{c}}}{L_{3}} \\
A_{23}=0 \\
A_{24}=0 \\
C_{\mathrm{S}}=M_{\mathrm{c}}+M_{\mathrm{cf}}
\end{gathered}
$$

$$
A_{31}=m_{\mathrm{p}}\left(1-\frac{a}{L_{3}}\right)\left(1-\frac{L+R_{\text {pin }}+L_{2}}{L_{1}+L_{2}+L+R_{\text {pin }}}\right)\left(L_{2}+L+R_{\text {pin }}\right)
$$$$
+m_{\mathrm{rod}}\left(1-\frac{a}{L_{3}}\right)\left(1-\frac{\frac{L}{2}+R_{\mathrm{pin}}}{L_{1}+L_{2}+L+R_{\mathrm{pin}}}\right)\left(\frac{L}{2}+R_{\mathrm{pin}}\right)
$$$$
-\frac{I_{q}\left(1-\frac{a}{L_{3}}\right)}{L_{1}+L_{2}+L+R_{\text {pin }}}
$$

$$
\begin{aligned}
A_{32}= & m_{\mathrm{p}} \frac{a}{L_{3}}\left(1-\frac{L+R_{\text {pin }}+L_{2}}{L_{1}+L_{2}+L+R_{\text {pin }}}\right)\left(L_{2}+L+R_{\text {pin }}\right) \\
& +m_{\text {rod }} \frac{a}{L_{3}}\left(1-\frac{\frac{L}{2}+R_{\text {pin }}}{L_{1}+L_{2}+L+R_{\text {pin }}}\right)\left(\frac{L}{2}+R_{\text {pin }}\right) \\
& -\frac{I_{\mathrm{q}} \cdot \frac{a}{L_{3}}}{L_{1}+L_{2}+L+R_{\text {pin }}} \\
A_{33}= & m_{\mathrm{p}} \frac{L+R_{\text {pin }}+L_{2}}{L_{1}+L_{2}+L+R_{\text {pin }}}\left(L+R_{\text {pin }}+L_{2}\right) \\
& +m_{\text {rod }} \frac{\frac{L}{2}+R_{\text {pin }}}{L_{1}+L_{2}+L+R_{\text {pin }}}\left(\frac{L}{2}+R_{\text {pin }}\right)+\frac{I_{\mathrm{q}}}{L_{1}+L_{2}+L+R_{\text {pin }}}
\end{aligned}
$$

$$
A_{34}=0
$$




$$
\begin{gathered}
C_{T}=M_{\mathrm{p}}+M_{\mathrm{pf}} \\
A_{41}=R_{\mathrm{c}} \cos \varphi\left[(1-j) m_{\mathrm{cr}} j\left(1-\frac{a}{L_{3}}\right)\right] \\
A_{42}=R_{\mathrm{c}} \cos \varphi\left[(1-j) m_{\mathrm{cr}} j\right] \\
A_{43}=0 \\
A_{44}=R_{\mathrm{c}} \cos \varphi\left[\frac{I_{\mathrm{cr}} I_{4}}{l_{\mathrm{rt}} \cos \theta}+\left(m_{\mathrm{cp}}+2 m_{\mathrm{c}}+m_{\mathrm{rod}}+m_{\mathrm{p}}+m_{\mathrm{cr}}\right) I_{1} \tan \theta\right. \\
-m_{\mathrm{cr}}(1-j) \tan \theta R_{\mathrm{c}} \sin \varphi+(1-j)^{2} m_{\mathrm{cr}} R_{\mathrm{c}} \cos \varphi \\
\left.-m_{\mathrm{cr}}(1-j) \tan \theta j l_{\mathrm{rt}} I_{4} \sin \theta+(1-j) \tan \theta R_{\mathrm{c}} \sin \varphi\right] \\
+R_{\mathrm{c}} \sin \varphi\left(m_{\mathrm{cp}}+2 m_{\mathrm{c}}+m_{\mathrm{rod}}+m_{\mathrm{p}}+m_{\mathrm{cr}}\right) I_{1}+J \\
C_{O}=-R_{\mathrm{c}} \cos \varphi\left(Z_{1}+Z_{2}+Z_{3}+Z_{4}\right)-R_{\mathrm{c}} \sin \varphi\left[-\left(m_{\mathrm{cp}}+2 m_{\mathrm{c}}\right.\right. \\
\left.+m_{\mathrm{rod}}+m_{\mathrm{p}}+m_{\mathrm{cr}}\right) g+\left(m_{\mathrm{cp}}+2 m_{\mathrm{c}}+m_{\mathrm{rod}}+m_{\mathrm{p}}\right. \\
\left.\left.+m_{\mathrm{cr}}\right)\left(I_{2}+I_{3}\right) \dot{\varphi}^{2}-F_{\mathrm{g}}-F_{\mathrm{pf}}-2 F_{\mathrm{cf}}\right]
\end{gathered}
$$

where

$$
\begin{gathered}
I_{1}=\left(l_{\mathrm{rt}}^{2}-B_{1}^{2}\right)^{-0.5} R_{\mathrm{c}}^{2} \sin \varphi \cos \varphi+R_{\mathrm{c}} \sin \varphi \\
I_{2}=R_{\mathrm{c}} \cos \varphi+\left(R_{\mathrm{c}} B_{1} \cos \varphi\right)^{2}\left(l_{\mathrm{rt}}^{2}-B_{1}^{2}\right)^{-1.5} \\
I_{3}=\left[\left(R_{\mathrm{c}} \cos \varphi\right)^{2}-R_{\mathrm{c}} B_{1} \sin \varphi\right]\left(l_{\mathrm{rt}}^{2}-B_{1}^{2}\right)^{-0.5} \\
I_{4}=\frac{R_{\mathrm{c}} \cos \varphi}{l_{\mathrm{rt}} \cos \theta} \\
I_{5}=-\left[\left(\frac{R_{\mathrm{c}} \cos \varphi}{l_{\mathrm{rt}} \cos \theta}\right)^{2} \tan \theta+\frac{R_{\mathrm{c}} \sin \varphi}{l_{\mathrm{rt}} \cos \theta}\right] \\
Z_{2}=\left[-\left(m_{\mathrm{cp}}+2 m_{\mathrm{c}}+m_{\mathrm{rod}}+m_{\mathrm{p}}+m_{\mathrm{cr}}\right) g\right. \\
+\left(m_{\mathrm{cp}}+2 m_{\mathrm{c}}+m_{\mathrm{rod}}+m_{\mathrm{p}}+m_{\mathrm{cr}}\right)\left(I_{2}+I_{3}\right) \dot{\varphi}^{2} \\
\left.-F_{\mathrm{g}}-F_{\mathrm{pf}}-2 F_{\mathrm{ct}}\right] \tan \theta \\
Z_{3}=-(1-j)^{2} m_{\mathrm{cr}} R_{\mathrm{c}} \sin \varphi \dot{\varphi}^{2} \\
Z_{4}=(1-j) \tan \theta\left\{m_{\mathrm{cr}} g-m_{\mathrm{cr}}\left[j l_{\mathrm{rt}}\left(\cos \theta \dot{\theta}^{2}+I_{5} \dot{\varphi}^{2} \sin \theta\right)\right.\right. \\
\left.\left.+R_{\mathrm{c}}\left(\cos \varphi \dot{\varphi}^{2}\right)\right]\right\} \\
Z_{5}=-m_{\mathrm{cr}}(1-j) R_{\mathrm{c}} \cos \varphi \\
Z_{6}=-m_{\mathrm{cr}} j\left(1-\frac{a}{L_{3}}\right)
\end{gathered}
$$

$$
\begin{gathered}
Z_{7}=-m_{\mathrm{cr}} j \frac{a}{L_{3}} \\
Z_{8}=m_{\mathrm{cr}}(1-j) R_{\mathrm{c}} \sin \varphi \dot{\varphi}^{2} \\
Z_{9}=-m_{\mathrm{cr}} j l_{\mathrm{rt}} I_{4} \sin \theta-m_{\mathrm{cr}} R_{\mathrm{c}} \sin \varphi \\
Z_{10}=-m_{\mathrm{cr}} j l_{\mathrm{rt}} \cos \theta \dot{\theta}^{2}-m_{\mathrm{cr}} j l_{\mathrm{rt}} \sin \theta I_{5} \dot{\varphi}^{2}-m_{\mathrm{cr}} R_{\mathrm{c}} \cos \varphi \dot{\varphi}^{2}
\end{gathered}
$$

where $g$ is the gravitational acceleration. The variables $a, b, L_{1}, L_{2}, L_{3}$, and $L$ are shown in Fig. 2 and defined in the Nomenclature Section. In addition, $l_{\mathrm{rt}}$ represents the length of the connecting rod, as shown in Fig. 3, and $j=l_{\mathrm{st}} / l_{\mathrm{rt}}$.

Open Access: The articles published in this journal are distributed under the terms of the Creative Commons Attribution 4.0 International License (http:// creativecommons.org/licenses/by/4.0/), which permits unrestricted use, distribution, and reproduction in any medium, provided you give appropriate credit to the original author(s) and the source, provide a link to the Creative Commons license, and indicate if changes were made.

The images or other third party material in this article are included in the article's Creative Commons licence, unless indicated otherwise in a credit line to the material. If material is not included in the article's Creative Commons licence and your intended use is not permitted by statutory regulation or exceeds the permitted use, you will need to obtain permission directly from the copyright holder.

To view a copy of this licence, visit http://creativecommons.org/licenses/by/4.0/.

\section{References}

[1] Holmberg K, Erdemir A. Influence of tribology on global energy consumption, costs and emissions. Friction 5(3): 263-284 (2017)

[2] Sun Y, Yan X, Yuan C, Bai X. Insight into tribological problems of green ship and corresponding research progresses. Friction 6(4): 472-483 (2018)

[3] Livanos G A, Kyrtatos N P. Friction model of a marine diesel engine piston assembly. Tribol Int 40: 1441-1453 (2007)

[4] Li R, Meng X, Li W, Dong J. A new comprehensive tribodynamic analysis for lubricated translational joints in lowspeed two-stroke marine engines. Int $J$ Engine Res, 21: 1336-1361 (2020) 
[5] Wong V W, Tung S C. Overview of automotive engine friction and reduction trends-Effects of surface, material, and lubricant-additive technologies. Friction 4(1): 1-28 (2016)

[6] Raptotasios S I, Sakellaridis N F, Papagiannakis R G, Hountalas D T. Application of a multi-zone combustion model to investigate the NOx reduction potential of two-stroke marine diesel engines using EGR. Appl Energ 157: 814-823 (2015)

[7] Theotokatos G. On the cycle mean value modelling of a large two-stroke marine diesel engine. P I Mech Eng M-J Eng 224: 193-205 (2010)

[8] Stachowiak G W. How tribology has been helping us to advance and to survive. Friction 5(3): 233-247 (2017)

[9] Ali M K A, Hou X, Abdelkareem M A A. Anti-wear properties evaluation of frictional sliding interfaces in automobile engines lubricated by copper/graphene nanolubricants. Friction 8(5): 905-916 (2020)

[10] Li R, Meng X, Xie Y. A tribological analysis on stuffing box-piston rod system of low-speed marine diesel engines. Int J Engine Res 20: 911-930 (2019)

[11] Hoang AT. A review on fuels used for marine diesel engines. J Mech Eng Res Dev 41(4): 22-23 (2018)

[12] Li R, Meng X, Xie Y. A new coupling tribodynamic model of crosshead slipper-guide system and piston skirt-liner system of low-speed marine diesel engines. Tribol Int 117: 189-205 (2018)

[13] Li T, Ma X, Lu X, Wang C, Jiao B, Xu H, et al. Lubrication analysis for the piston ring of a two-stroke marine diesel engine taking account of the oil supply. Int $J$ Engine Res 22: 949-962 (2021)

[14] Overgaard H, Klit P, Vølund A. Lubricant transport across the piston ring with flat and triangular lubrication injection profiles on the liner in large two-stroke marine diesel engines. P I Mech Eng J-J Eng 232: 380-390 (2018)

[15] Liu Z, Meng X, Wen C, Yu S, Zhou Z. On the oil-gas-solid mixed bearing between compression ring and cylinder liner under starved lubrication and high boundary pressures. Tribol Int 140:105869 (2019).

[16] Zhang Z, Liu J, Wu T, Xie Y. Effect of carbon nanotubes on friction and wear of a piston ring and cylinder liner system under dry and lubricated conditions. Friction 5(2): 147-154 (2017)

[17] Wakuri Y, Ono S, Soejima M. On the Lubrication of Crosshead-pin Bearing with Eccentric Journal. Bulletin of JSME 25: 1312-1320 (1982)

[18] Wakuri Y, Kitahara T, Hamatake T, Soejima M, Hirata A. Experimental studies on an externally pressurized crosshead-pin bearing. Trans Jpn Soc Mech Eng C 63: 2832-2838 (1997)
[19] Moon S M, Cho Y J, Kim T W. Evaluation of lubrication performance of crank pin bearing in a marine diesel engine. Friction 6(4): 464-471 (2018)

[20] Abanteriba S. The Analysis of the lubrication condition and friction losses of a single acting cross head guide shoe of a low speed cross head diesel engine: Part I-An alogrithm for the prediction of oil film thickness. Tribol T 43: 665-670 (2000)

[21] Abanteriba S. The Analysis of the lubrication condition and friction losses of a single acting cross head guide shoe of a low speed cross head diesel engine: Part II-A practical model for the determination of the oil film thickness. Tribol $T \mathbf{4 3}$ (2000)

[22] Abanteriba S. The Analysis of the lubrication condition and friction losses of a single acting cross head guide shoe of a low speed cross head diesel engine: PART III-Friction and its minimization. Tribol T 43: 830-836 (2000)

[23] Fang C, Meng X, Kong X, Zhao B, Huang H. Transient tribo-dynamics analysis and friction loss evaluation of piston during cold-and warm-start of a SI engine. Int J Mech Sci 133: 767-787 (2017)

[24] Liu R, Meng X, Li P. Transient tribodynamic analysis of crankshaft-main bearing system during engines starting up. P I Mech Eng J-J Eng 232: 535-549 (2017)

[25] Liu R, Meng X, Cui Y. Influence of numerous start-ups and stops on tribological performance evolution of engine main bearings. Int J Engine Res 21: 1362-1380 (2020)

[26] Monmousseau P, Fillon M. Transient thermoelastohydrodynamic analysis for safe operating conditions of a tilting-pad journal bearing during start-up. Tribol Int 33: 225-231 (2000)

[27] Meng X, Fang C, Xie Y. Transient tribodynamic model of piston skirt-liner systems with variable speed effects. Tribol Int 94: 640-651 (2016)

[28] Qasim S A, Chaudhri U F, Malik M A. Analyzing viscoelastic effects in piston skirts EHL at small radial clearances in initial engine start up. Tribol Int 45: 16-29 (2012)

[29] Li R, Meng X H. Influence of temperature on lubrication viscosity in the crosshead slipper andpiston skirt. J Harbin Engineering Univ 40(12): 1980-1985 (2019) (in Chinese)

[30] Li R, Meng X H. Analysis of factors affecting tribo- dynamics of guide shoe of marine diesel engines. J Shanghai Jiaotong Univ 54: 1035-1044 (2020)

[31] Wang W, He Y, Zhao J, Mao J, Hu Y, Luo J. Optimization of groove texture profile to improve hydrodynamic lubrication performance: Theory and experiments. Friction 8(1): 83-94 (2020)

[32] Patir N, Cheng H. An average flow model for determining effects of three-dimensional roughness on partial hydrodynamic lubrication. J Lubr Technol 100: 12-17 (1978) 
[33] Patir N, Cheng H. Application of average flow model to lubrication between rough sliding surfaces. J Lubr Technol 101: 220-229 (1979)

[34] Wu C, Zheng L. An Average Reynolds Equation for Partial Film Lubrication With a Contact Factor. J Tribol 111: 83-90 (1989)

[35] Meng F M. On influence of cavitation in lubricant upon tribological performances of textured surfaces. Opt Laser Technol 48: 422-431 (2013)

[36] Jakobsson B. The Finite Journal Bearing, Considering Vaporization. Trans Chalmers Univ of Tech 190 (1957)

[37] Olsson KO. Cavitation in dynamically loaded bearings. Trans Chalmers Univ of Tech 308 (1957)

[38] Morris N, Rahmani R, Rahnejat H, King P, Fitzsimons B. The influence of piston ring geometry and topography on friction. P I Mech Eng J-J 227: 141-153 (2013)

[39] Guo Y, Lu X, Li W, He T, Zou D. A mixed-lubrication model considering elastoplastic contact for a piston ring and application to a ring pack. P I Mech Eng J-J 229: 174-188 (2014)

[40] Fang C, Meng X, Xie Y, Wen C, Liu R. An improved technique for measuring piston-assembly friction and comparative analysis with numerical simulations: Under motored condition. Mech Syst Signal Pr 115: 657-176 (2019)

[41] Hu Y, Cheng H S, Arai T, Kobayashiy Y, Aoyama S. Numerical simulation of piston ring in mixed lubrication-A nonaxisymmetrical analysis. Trans Asme 116: 470-478 (1994)

[42] Greenwood J A, Tripp J H. The contact of two nominally flat rough surfaces. P I Mech Eng E-J Pro 185: 625-634 (1970)

[43] Gu C, Meng X, Zhang D. Analysis of the coated and textured ring/liner conjunction based on a thermal mixed lubrication model. Friction 6(4): 420-431 (2017)

[44] Meng X, Xie Y. A new numerical analysis for piston skirt-liner system lubrication considering the effects of connecting rod inertia. Tribol Int 47: 235-243 (2012)

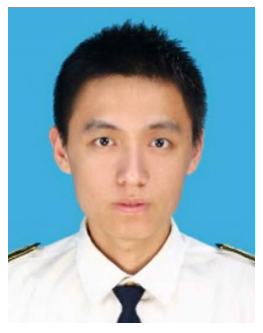

Rui LI. He received his bachelor degree in the School of Energy and Power Engineering in 2016 from Wuhan University of Technology, Wuhan, China. After then, he is a
[45] Meng F M, Wang W Z, Hu Y Z, Wang H. Numerical analysis of combined influences of inter-asperity cavitation and elastic deformation on flow factors. Proc Imeche 221: 815-827 (2007)

[46] Meng F M, Qin D T, Chen H B, Hu Y Z, Wang H. Study on combined influence of inter-asperity cavitation and elastic deformation of non-Gaussian surfaces on flow factors. $P I$ Mech Eng C-J Mec 222: 1039-1048 (2008)

[47] Meng F M, Cen S Q, Hu Y Z, Wang H. On elastic deformation, inter-asperity cavitation and lubricant thermal effects on flow factors. Tribol Int 42: 260-274 (2009)

[48] Meng F, Wang QJ, Hua D, Liu S. A simple method to calculate contact factor used in average flow model. $J$ Tribol 132: 269-272 (2010)

[49] Cash J R. The integration of stiff initial value problems in ODEs using modified extended backward differentiation formulae. Comput Math Appl 9: 645-657 (1983)

[50] Cash J R. Modified extended backward differentiation formulae for the numerical solution of stiff initial value problems in ODEs and DAEs. J Comput Appl Math 125: $117-130$ (2000)

[51] Fang C, Meng X, Lu Z, Wu G, Tang D, Zhao B. Modeling a lubricated full-floating pin bearing in planar multibody systems. Tribol Int 131: 222-237 (2019)

[52] Fang C, Meng X, Xie Y. A piston tribodynamic model with deterministic consideration of skirt surface grooves. Tribol Int 110:232-251 (2017)

[53] Zhang Z, Liu J, Xie Y. Design approach for optimization of a piston ring profile considering mixed lubrication. Friction 4(4): 335-346 (2016)

[54] Fan H, Zhang J, Zhang W, Liu B. Multiparameter and multiobjective optimization design based on orthogonal method for mixed flow fan. Energies, in press, DOI 10.3390/ en13112819 (2020)

[55] Xu Y, Tan L, Cao S, Qu W. Multiparameter and multiobjective optimization design of centrifugal pump based on orthogonal method. P I Mech Eng C-J Mec 231: 2569-2579 (2017)

Ph.D. student in the School of Mechanical Engineering at Shanghai Jiaotong University. His research interests include multibody dynamics, simulation, and testing technology for the tribological phenomenon of mechanical systems. 


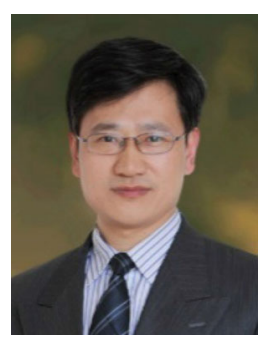

Xianghui MENG. Professor, obtained his bachelor degree and master degree in 1995 and 1999 from Xi'an Jiaotong University, and Ph.D. degree in 2006 from Shanghai Jiaotong University. He was invited to visit the Massachusetts Institute of Technology (MIT) during 2011-2012. His current position is a professor and doctorial supervisor at School of Mechanical Engineering, Shanghai Jiaotong University. His interested research areas include the tribology of internal combustion engines, low friction design, and wear mechanism. He has presided many research projects and has published more than 50 papers on international engineering journals. 